\title{
High temperature impedance spectroscopy of barium stannate, $\mathrm{BaSnO}_{3}$
}

\author{
SHAIL UPADHYAY \\ Department of Physics, Institute of Technology, Banaras Hindu University, Varanasi 221 005, India
}

MS received 29 May 2012; revised 14 July 2012

\begin{abstract}
Polycrystalline powder of $\mathrm{BaSnO}_{3}$ was prepared at $1300{ }^{\circ} \mathrm{C}$ using a high-temperature solid-state reaction technique. X-ray diffraction analysis indicated the formation of a single-phase cubic structure with lattice parameter: $a=(4 \cdot 1158 \pm 0.0003) \AA$. The synthesized powder was characterized using X-ray diffraction (XRD) scanning electron micrographs, energy dispersive $\mathrm{X}$-ray analysis, differential thermal analysis, thermogravimetric analysis and Fourier transform infrared techniques. Electrical properties were studied using a.c. impedance spectroscopy technique in the temperature range of $50-650{ }^{\circ} \mathrm{C}$ and frequency range of $10 \mathrm{~Hz}-13 \mathrm{MHz}$. The complex impedance plots at temperature $\geq 300{ }^{\circ} \mathrm{C}$ show that total impedance is due to the contributions of grains, grain boundaries and electrode. Resistance of these contributions has been determined. Variation of these resistances with temperature shows the presence of two different regions with different slopes. The nature of variation for the above three resistances, in both the temperature regions confirms that conducting species (phases) responsible for grain, grain boundaries and electrode are the same. Based on the value of activation energy, it is proposed that conduction via hopping of doubly ionized oxygen vacancies $\left(V_{0}^{\bullet \bullet}\right)$ is taking place in the temperature region of $300-450{ }^{\circ} \mathrm{C}$, whereas in the temperature region of $450-650{ }^{\circ} \mathrm{C}$, hopping of proton, i.e. $\mathrm{OH}^{\bullet}$ ions occurs.
\end{abstract}

Keywords. Ceramics; oxides; infrared spectroscopy; electrical properties; electrical conductivity.

\section{Introduction}

Alkaline earth stannates have the general formula, $\mathrm{MSnO}_{3}$ $(\mathrm{M}=\mathrm{Ba}, \mathrm{Sr}, \mathrm{Ca}$ and $\mathrm{Pb})$. These oxides are structurally analogous to the naturally occurring mineral pervoskite, $\mathrm{CaTiO}_{3}$. Barium stannate $\left(\mathrm{BaSnO}_{3}\right)$ is a cubic pervoskite oxide compound which behaves as an $n$-type semiconductor with a wide bandgap of $3.4 \mathrm{eV}$. It is thermally stable up to $2000{ }^{\circ} \mathrm{C}$ (Shimizu et al 1985; Larramona et al 1989; Cava et al 1990; Smit et al 1992). Pure and doped barium stannates have found important applications in materials science and technology due to their dielectric properties, semiconducting behaviour and high thermal stability. Owing to these characteristics properties, $\mathrm{BaSnO}_{3}$-based ceramics are becoming more and more important in materials technology. They can be used to prepare thermally stable capacitors and to fabricate ceramic boundary layer capacitors (Prokopale 1976; Vivekanandan and Kutty 1990; Wang et al 2003; Kumar et al 2005a). Moreover, barium stannate can also be used as a functional material for semiconductor gas and humidity sensor (Ostrick et al 1997; Tao et al 2000; Gopal Reddy et al 2001; Cerda et al 2002; Kocemba et al 2007; Upadhyay and Kavita 2007; Doroflet et al 2012) and photocatalytic applications (Borse et al 2007; Yuan et al 2007; Zhang et al 2008). Due to these noteworthy applications, considerable amount

(supadhyay.app@itbhu.ac.in; shail72@yahoo.com) of research has been devoted to the study of synthesis of this material (Kutty and Vivekanandan 1987; Upadhyay et al 1997; Azad and Hon 1998; Pfaff et al 1998; Song and Kim 2001; Roberto et al 2006; Lu and Schmidt 2007, 2008; Wang et al 2007; Ramdas and Vijayraghavan 2010; Deepa et al 2011).

Literature survey indicates that electrical properties of $\mathrm{BaSnO}_{3}$ have basically been studied by conventional (d.c.) methods (Smolensi et al 1955; Raevski et al 1983). A few reports are available on characterization of this material by impedance spectroscopy but only in the temperature range of $300-500{ }^{\circ} \mathrm{C}$ (Kumar et al 2005a, b, 2006a, b, 2007; Kumar and Choudhary 2007). $\mathrm{BaSnO}_{3}$-based materials have recently been proposed as high temperature protonic conductors (Murugaraj et al 1997; Schober 1998; Bevillon et al 2008; Wang et al 2011) with potential applications in fuel cells. Electrical characterization by impedance method will be worthwhile for development of this material for fuel cell application. A systematic analysis of its electrical properties by a.c. technique of impedance analysis has, however, not been carried out at high temperatures (above $300{ }^{\circ} \mathrm{C}$ ). The present paper reports our investigations on electrical properties of $\mathrm{BaSnO}_{3}$. Impedance analysis approach has been used to separate the real and imaginary components of electrical response and estimate the electrical relaxation time $\left(\tau_{\max }\right)$ at different temperatures. Impedance spectrum and electrical conductivity have been measured as a function of temperature $\left(50-650{ }^{\circ} \mathrm{C}\right)$ and frequency $(10 \mathrm{~Hz}-13 \mathrm{MHz})$. 
Complex plane impedance spectroscopy is considered to be a promising non-destructive testing method for analysing the electrical processes occurring in a compound on application of a.c. signal as input perturbation. The output response of polycrystalline compound represents grain, grain boundary and interfacial properties with different time constants. Using this technique, one can separate out resistance of grain interiors, grain boundaries and electrode. From these data and knowledge of the sample dimensions, the bulk (or grain interior) and grain boundaries conductivities can be estimated in rather straightforward manner. The equivalent electrical circuit shown below is widely used to fit impedance data of polycrystalline materials. In this equivalent circuit, it is desired to separate each of the Resistance-capacitance $(R C)$ components and measure values. This can be seen from the equation for the impedance of this circuit.

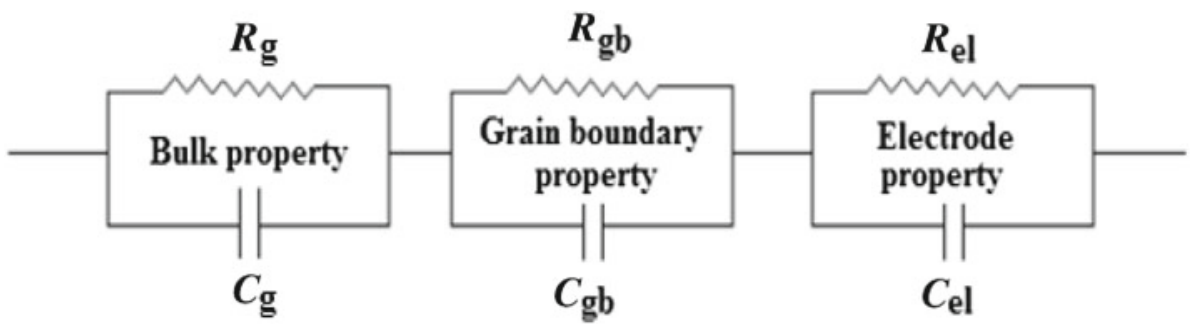

$$
\begin{aligned}
Z= & Z^{\prime}-j Z^{\prime \prime}=\left(1 / R_{\mathrm{g}}+j \omega C_{\mathrm{g}}\right)^{-1} \\
& +\left(1 / R_{\mathrm{gb}}+j \omega C_{\mathrm{gb}}\right)^{-1}+\left(1 / R_{\mathrm{el}}+j \omega C_{\mathrm{el}}\right)^{-1},(1) \\
Z^{\prime}= & {\left[\left(R_{\mathrm{g}}\right) /\left(1+\omega^{2} C_{\mathrm{g}}^{2} R_{\mathrm{g}}^{2}\right)+\left(R_{\mathrm{gb}}\right) /\left(1+\omega^{2} C_{\mathrm{gb}}^{2} R_{\mathrm{gb}}^{2}\right)\right.} \\
& \left.+\left(R_{\mathrm{el}}\right) /\left(1+\omega^{2} C_{\mathrm{el}}^{2} R_{\mathrm{el}}^{2}\right)\right] \\
Z^{\prime \prime}= & {\left[\left(\omega R_{\mathrm{g}}^{2} C_{\mathrm{g}}\right) /\left(1+\omega^{2} C_{\mathrm{g}}^{2} R_{\mathrm{g}}^{2}\right)+\left(\omega R_{\mathrm{gb}}^{2} C_{\mathrm{gb}}\right)\right.} \\
& \left./\left(1+\omega^{2} C_{\mathrm{gb}}^{2} R_{\mathrm{gb}}^{2}\right)+\left(\omega R_{\mathrm{el}}^{2} C_{\mathrm{el}}\right) /\left(1+\omega^{2} C_{\mathrm{el}}^{2} R_{\mathrm{el}}^{2}\right)\right] .
\end{aligned}
$$

Thus, complex plane impedance plots $\left(Z^{\prime \prime}\right.$ vs $\left.Z^{\prime}\right)$ of many polycrystalline materials exhibit an arc at high frequency, a second arc at lower frequencies and a third arc at even lower frequencies. In complex plane impedance plot, ideal semicircle (whose centre lies on the $Z^{\prime}$ axis) appears only when contribution to this arc is having single relaxation time. If distribution of relaxation times exists, then one gets a depressed arc instead of an ideal semicircle. The frequency at the apex of each of the arcs corresponds to the characteristic frequency, $\omega_{\mathrm{o}}$, of the respective $(R C)$ subcircuit. The characteristic frequency, $\omega_{0}$, of a material or a region of a material is equal to $1 / R C$. Since $R$ and $C$ depend on geometric parameters in an inverse manner, $\omega_{\mathrm{o}}$ is an intrinsic material property, independent of geometric consideration, and equal to $1 / \rho \varepsilon_{0} \varepsilon_{\mathrm{r}}$ (where $\rho$, resistivity $=1 / \sigma, \varepsilon_{\mathrm{o}}$, permittivity of free space and $\varepsilon_{\mathrm{r}}$, relative permittivity of material) (Burn and Neirman 1984; MacDonald and Johnson 1987; Haile et al 1998).

\section{Experimental}

Barium stannate was synthesized by solid state ceramic method. The starting compounds used for preparation of the sample were $\mathrm{BaCO}_{3}$ (Merck, India, purity 99.0\%) and $\mathrm{SnO}_{2}$ (Aldrich-Sigma, USA, purity 99.9\%). Stoichiometric amounts of these compounds were mixed in a ball mill for $6 \mathrm{~h}$ using acetone as the mixing media. The homogeneous mixture was heated in an alumina crucible up to $1000^{\circ} \mathrm{C}$ and held at this temperature for $8 \mathrm{~h}$. Polyvinyl alcohol was added to the calcined powder for the fabrication of pellets, which was burnt out during high temperature sintering. Circular disc-shaped pellets were prepared by applying a uniaxial load of 5 ton. These pellets were subsequently sintered at $1250{ }^{\circ} \mathrm{C}$ for $12 \mathrm{~h}$. To improve homogeneity, sintered pellets were crushed, re-pelletized and re-sintered at $1300{ }^{\circ} \mathrm{C}$ for $12 \mathrm{~h}$.

A preliminary study on compound formation and structural parameter was carried out using X-ray diffraction (XRD) technique with an X-ray powder diffractometer (Rigaku Miniflex). XRD pattern of the calcined powder was recorded at room temperature with $\mathrm{CuK} \alpha$ radiation $(1.5418 \AA)$ in a wide range of Bragg's angles $2 \theta\left(20^{\circ} \leq\right.$ $\left.2 \theta \leq 80^{\circ}\right)$ at a scan speed of $4^{\circ} / \mathrm{min}$. For scanning electron micrographs (SEM) and energy dispersive X-ray analysis (EDXA), freshly fractured surfaces of the sintered pellets were gold-sputtered and scanned in different regions using a JEOL JSM-5800 scanning electron microscope. Thermal analysis (DTA and TGA curves) of the sample was made using a Perkin-Elmer (Model Pyrix EXST AR 6000) TGDTA instrument in the temperature range of $30-850{ }^{\circ} \mathrm{C}$ with a heating rate of $10{ }^{\circ} \mathrm{C}$ in nitrogen atmosphere. Fourier transform infrared (FTIR) spectra of the sample were recorded using Shimadzu (Model DF 803) Fourier transform infrared spectrometer in the wave number range of $400-4000 \mathrm{~cm}^{-1}$.

For impedance measurements, polished surfaces of the pellets were coated with high purity air-drying silver paste. 
These pellets were cured at $700{ }^{\circ} \mathrm{C}$ for $10 \mathrm{~min}$. Impedance measurements were done using a computer-controlled impedance analyser (HP 4192 A LF) over a wide range of temperatures $\left(50-650^{\circ} \mathrm{C}\right)$ and frequencies $(10 \mathrm{~Hz}-13 \mathrm{MHz})$.

\section{Results and discussion}

\subsection{Structural analysis}

XRD pattern of the powder sintered at $1250{ }^{\circ} \mathrm{C}$ is shown in figure 1(a). The figure shows that no new phase is formed

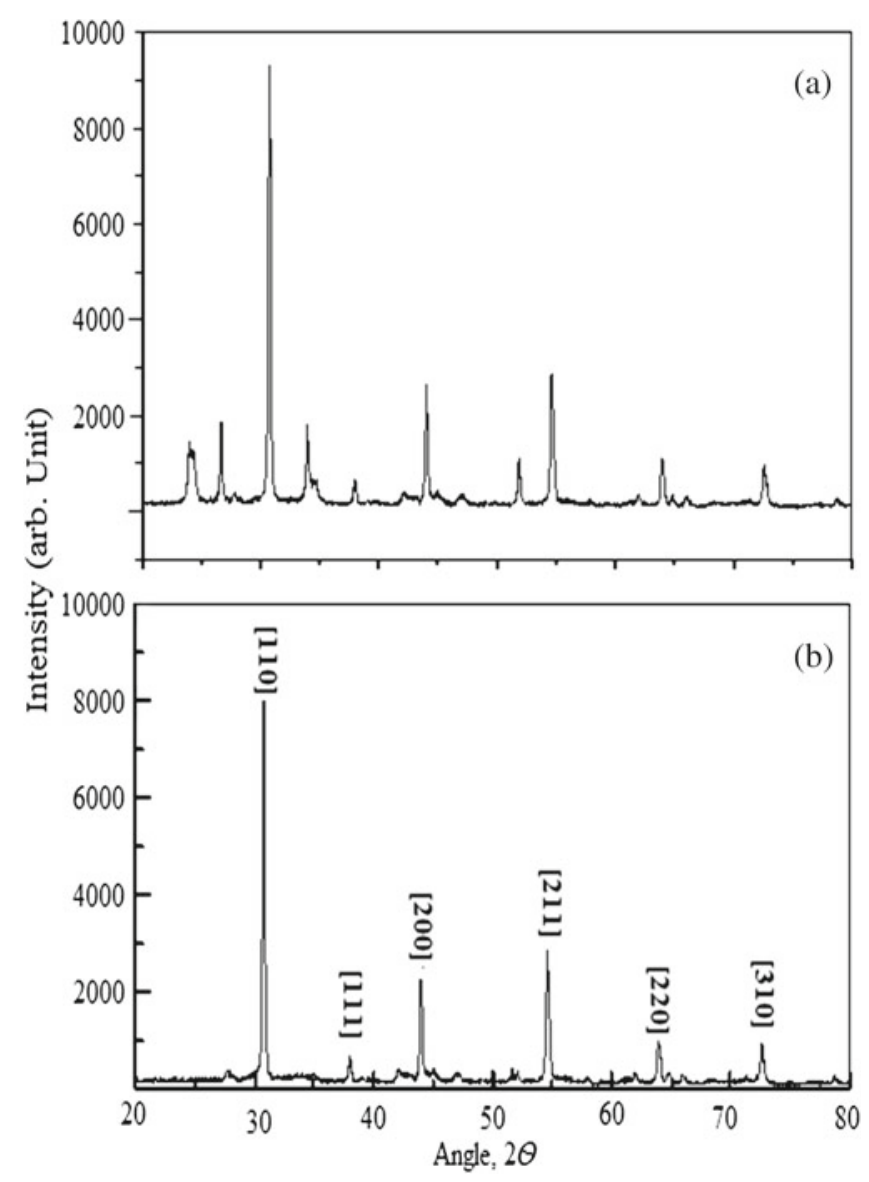

Figure 1. X-ray diffraction pattern of sample sintered at (a) $1250{ }^{\circ} \mathrm{C}$ and (b) $1300{ }^{\circ} \mathrm{C}$ of $\mathrm{BaSnO}_{3}$. in the powder except for small traces of $\mathrm{BaCO}_{3}$ and $\mathrm{SnO}_{2}$ which has been confirmed from the presence of low intensity peaks of these compounds. Figure 1(b) shows XRD pattern of powder sintered at $1300{ }^{\circ} \mathrm{C}$. In this figure, all the peaks are assigned to cubic structure of $\mathrm{BaSnO}_{3}$. XRD data of the sintered powder is given in table 1. Lattice parameter of the sample was calculated using a program known as CELL. Calculated lattice parameter is found to be $4.1158 \pm$ $0.0003 \AA$ and it agrees very well with the reported XRD data in the joint committee on powder diffraction standard (JCPDS) file (JCPDS card no. 15-0780) for $\mathrm{BaSnO}_{3}$ which indicates complete formation of $\mathrm{BaSnO}_{3}$. The crystallite size of the synthesized powder of $\mathrm{BaSnO}_{3}$ was calculated using the Debye-Scherrer equation

$$
D=0.9 \lambda / \beta \cos \theta_{\max },
$$

where $D$ is the crystallite size, $\lambda$ the wavelength of $\mathrm{CuK} \alpha$ radiation, $\beta$ the line width at half peak intensity and $\theta_{\max }$ the diffraction peak angle. Crystallite size calculated for all planes is given in table 1 . The average crystallite size was found to be $80 \mathrm{~nm}$.

Bulk density $\left(d_{\mathrm{b}}\right)$ of the sample was obtained using Archimedes' principle. Theoretical density $\left(d_{\mathrm{th}}\right)$ of the sample was calculated from the molecular weight of the samples and its lattice parameter. Percentage porosity was calculated using the formula:

$$
\% \text { Porosity }=\left[\left(d_{\mathrm{th}}-d_{\mathrm{b}}\right) /\left(d_{\mathrm{th}}\right)\right] \times 100 .
$$

Bulk density, theoretical density and percentage porosity of the sample are $5.97 \mathrm{~g} / \mathrm{cm}^{3}, 7.24 \mathrm{~g} / \mathrm{cm}^{3}$ and $18 \%$, respectively.

\subsection{Microstructural analysis}

SEM surface morphology of the sample (of three randomly chosen regions $\mathrm{A}, \mathrm{B}$ and $\mathrm{C}$ on the surface of the pellet) is shown in figure 2. It is observed that grain size of the sample is small $(<1 \mu \mathrm{m})$. Small grain size of the sample as compared to that reported in the literature is attributed to lower sintering temperature and time used for the synthesis (Smith and Welch 1960). Porous nature of the sample is also reflected in the SEM photographs. Similarity in

Table 1. XRD data of the synthesized $\mathrm{BaSnO}_{3}$ powder.

\begin{tabular}{ccccccc}
\hline $\begin{array}{c}\text { Angle } \\
\left(2 \theta_{\text {abs. }}\right)\end{array}$ & $\begin{array}{c}d_{\text {abs. }^{-}} \\
\text {values } \\
(\AA)\end{array}$ & $\begin{array}{c}d_{\text {ref. }} \\
\text { values } \\
(\AA)\end{array}$ & $\begin{array}{c}\text { Peak width } \\
\text { at half } \\
\text { intensity }\end{array}$ & $\begin{array}{c}\text { Peak } \\
\text { intensity }\end{array}$ & $\begin{array}{c}\text { Reflection } \\
\text { plane }\end{array}$ & $\begin{array}{c}\text { Crystallite } \\
\text { size } \\
(\mathrm{nm})\end{array}$ \\
\hline 30.6716 & 2.91248 & 2.9109 & $0 \cdot 1717$ & 2754.3 & 110 & 54 \\
37.8518 & $2 \cdot 37488$ & $2 \cdot 3775$ & 0.1685 & 61.97 & 111 & 60 \\
43.9431 & 2.05877 & 2.0585 & $0 \cdot 1602$ & 871.77 & 200 & 69 \\
54.5717 & 1.68026 & 1.6789 & $0 \cdot 1821$ & 1173.3 & 211 & 75 \\
63.9309 & 1.45499 & 1.4554 & 0.1918 & 510.55 & 220 & 94 \\
72.6007 & 1.30111 & 1.2999 & 0.2203 & 503.17 & 310 & 121 \\
\hline
\end{tabular}


appearance of SEM of all the three regions (A, B and C) indicates homogeneous nature of the sample and uniform distribution of porosity. Compositional homogeneity (in terms of concentration profile of the elements) has been probed by recording EDXA spectra of different regions of the sample. EDX spectrum of regions $\mathrm{A}, \mathrm{B}$ and $\mathrm{C}$ (corresponding to figure $2(a-c)$ ) is shown in figure 3 . Figure 3 shows the presence of $\mathrm{Sn}, \mathrm{Ba}$ and $\mathrm{O}$ peaks only. Composition of these elements is recorded in table 2. Quantification calculation
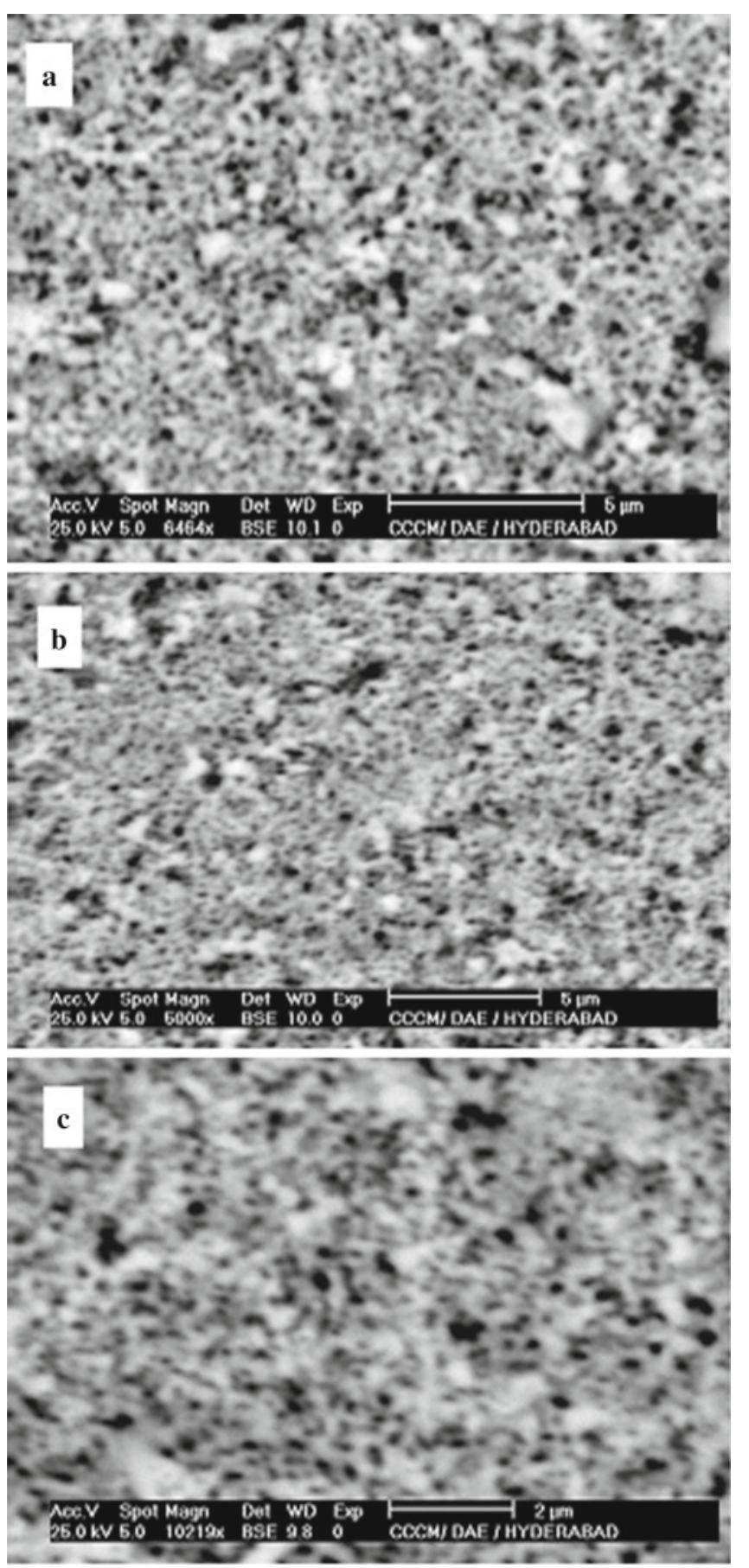

Figure 2. Scanning electron micrographs of randomly chosen three regions (a, $\mathbf{b}$ and $\mathbf{c})$ of $\mathrm{BaSnO}_{3}$. shows that atomic ratio of $\mathrm{Ba} / \mathrm{Sn}$ in all the three regions is approximately same (within the experimental error), which reflects the homogeneous nature of the synthesized powder.

\subsection{Thermal analysis}

Thermal characterization of the synthesized powder has been carried out using differential thermal analysis (DTA) and thermogravimetric analysis (TGA) up to $850{ }^{\circ} \mathrm{C}$ at a heating rate $10{ }^{\circ} \mathrm{C} / \mathrm{min}$ in nitrogen atmosphere. DTA and TGA curves of the powder are shown in figure 4. TGA exhibits an $8 \%$ total weight loss in three steps, the first step from $R T$ to $200{ }^{\circ} \mathrm{C}$ (with a loss of $3.6 \%$ ), the second step from 200 to $550{ }^{\circ} \mathrm{C}$ (with a loss of $1.2 \%$ ) and the third step from 550 to $850^{\circ} \mathrm{C}$ (with a loss of $3.2 \%$ ). Weight loss is mainly due to the removal of water adsorbed by the sample.

Enthalpy changes observed in the DTA curve at different temperatures can be attributed to surface reaction taking place in $\mathrm{BaSnO}_{3}$. There is no evidence of any phase transition taking place in the sample up to this temperature.

\section{$3.4 \quad$ FTIR spectroscopy}

Oxygen-hydrogen groups can be identified by using FTIR spectroscopy. FTIR spectrum of the synthesized powder of

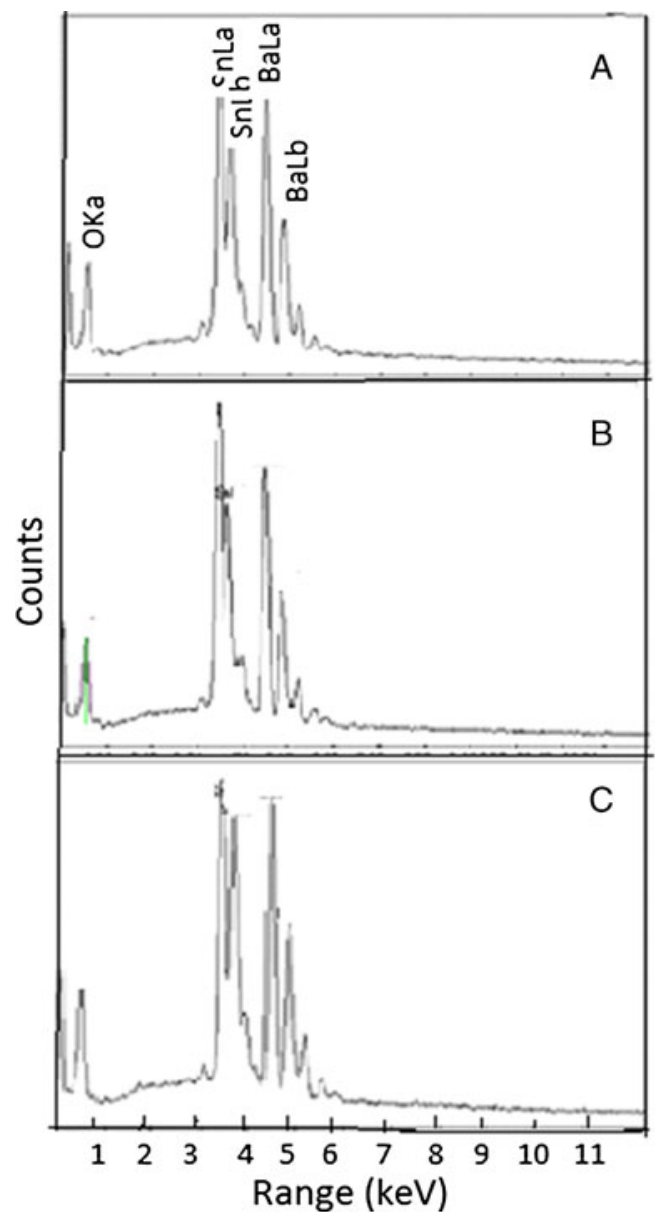

Figure 3. Energy dispersive $\mathrm{X}$-ray spectra of $\mathrm{BaSnO}_{3}$. 
Table 2. Concentration profile of elements by energy dispersive (EDX) analysis in three randomly chosen grains.

\begin{tabular}{|c|c|c|c|c|}
\hline \multirow[b]{2}{*}{ Region } & \multirow[b]{2}{*}{ Elements } & \multicolumn{2}{|c|}{ Atom \% } & \multirow{2}{*}{$\begin{array}{c}\mathrm{Sn} / \mathrm{Ba} \\
\text { ratio }\end{array}$} \\
\hline & & Theoretical & Experimental & \\
\hline \multirow[t]{4}{*}{ A } & Oxygen & 60 & 62.93 & \multirow[t]{4}{*}{1.009} \\
\hline & $\mathrm{Sn}$ & 20 & $18 \cdot 61$ & \\
\hline & $\mathrm{Ba}$ & 20 & 18.45 & \\
\hline & Total & 100 & 100 & \\
\hline \multirow[t]{4}{*}{ B } & Oxygen & 60 & $62 \cdot 82$ & \multirow[t]{4}{*}{1.018} \\
\hline & $\mathrm{Sn}$ & 20 & $18 \cdot 76$ & \\
\hline & $\mathrm{Ba}$ & 20 & 18.42 & \\
\hline & Total & 100 & 100 & \\
\hline \multirow[t]{4}{*}{$\mathrm{C}$} & Oxygen & 60 & $63 \cdot 13$ & \multirow[t]{4}{*}{$1 \cdot 014$} \\
\hline & $\mathrm{Sn}$ & 20 & $18 \cdot 56$ & \\
\hline & $\mathrm{Ba}$ & 20 & $18 \cdot 31$ & \\
\hline & Total & 100 & 100 & \\
\hline
\end{tabular}

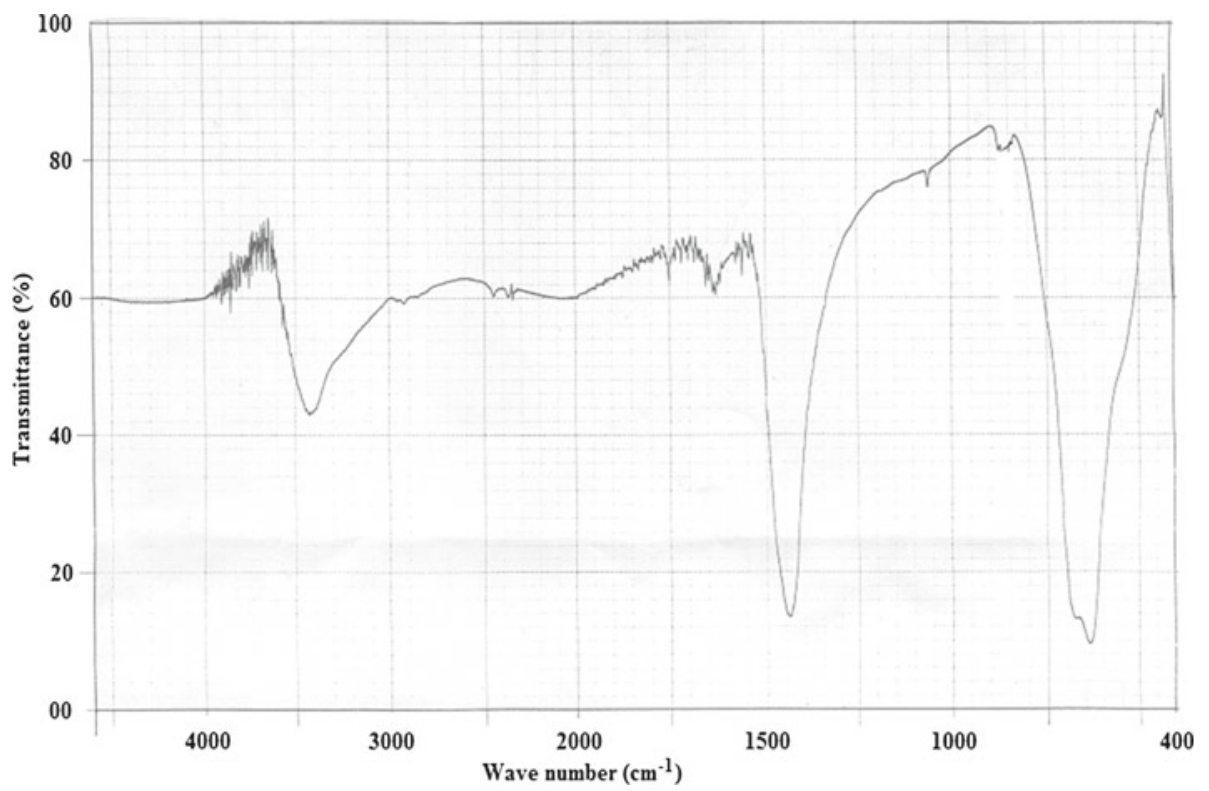

Figure 4. FTIR spectra of barium stannate, $\mathrm{BaSnO}_{3}$.

$\mathrm{BaSnO}_{3}$ is shown in figure 5. It is noticed that FTIR spectrum of this sample has mainly two extra peaks at 3450 and $1420 \mathrm{~cm}^{-1}$ as compared to FTIR spectrum of $\mathrm{BaSnO}_{3}$ reported in the literature (Gopal Reddy et al 2001). The peak at $3450 \mathrm{~cm}^{-1}$ is assigned to the stretching modes of $\mathrm{O}-\mathrm{H}$ bond and is related to water adsorbed at the surface of the sample. An intense band at $1420 \mathrm{~cm}^{-1}$ can be assigned to $\mathrm{M}-\mathrm{OH}$ group vibration (Animitsa et al 2011). Hence, the main part of the hydrogen atom is present in the form of hydroxide ions. Water insertion into the oxide structure can be represented as the process of the dissociative dissolution and formation of proton defects

$$
\mathrm{V}_{\mathrm{S}}^{x}+\mathrm{H}_{2} \mathrm{O}+2 \mathrm{O}_{\mathrm{o}} \rightarrow 2(\mathrm{OH})^{\bullet}+\mathrm{O}_{\mathrm{i}}^{\prime \prime},
$$

where all the species are written in accordance with KrögerVink notation of defects.

\subsection{Impedance analysis}

Complex impedance plots at different temperatures (in the range $150-650{ }^{\circ} \mathrm{C}$ ) of the sample are shown in figure 6 . At $150{ }^{\circ} \mathrm{C}$, a steep rising of $Z^{\prime \prime}$ (almost parallel to $Z^{\prime \prime}$ ) is observed. Similar plots have been observed at temperatures 50 and $100{ }^{\circ} \mathrm{C}$. As temperature increases to $200{ }^{\circ} \mathrm{C}$, curve bends toward real axis, i.e. $Z^{\prime}$ axis and takes the shape of a semicircle. At $250{ }^{\circ} \mathrm{C}$, two semicircular arcs have been observed, although the low frequency semicircle is incomplete due to lower limit of frequency of the impedance 


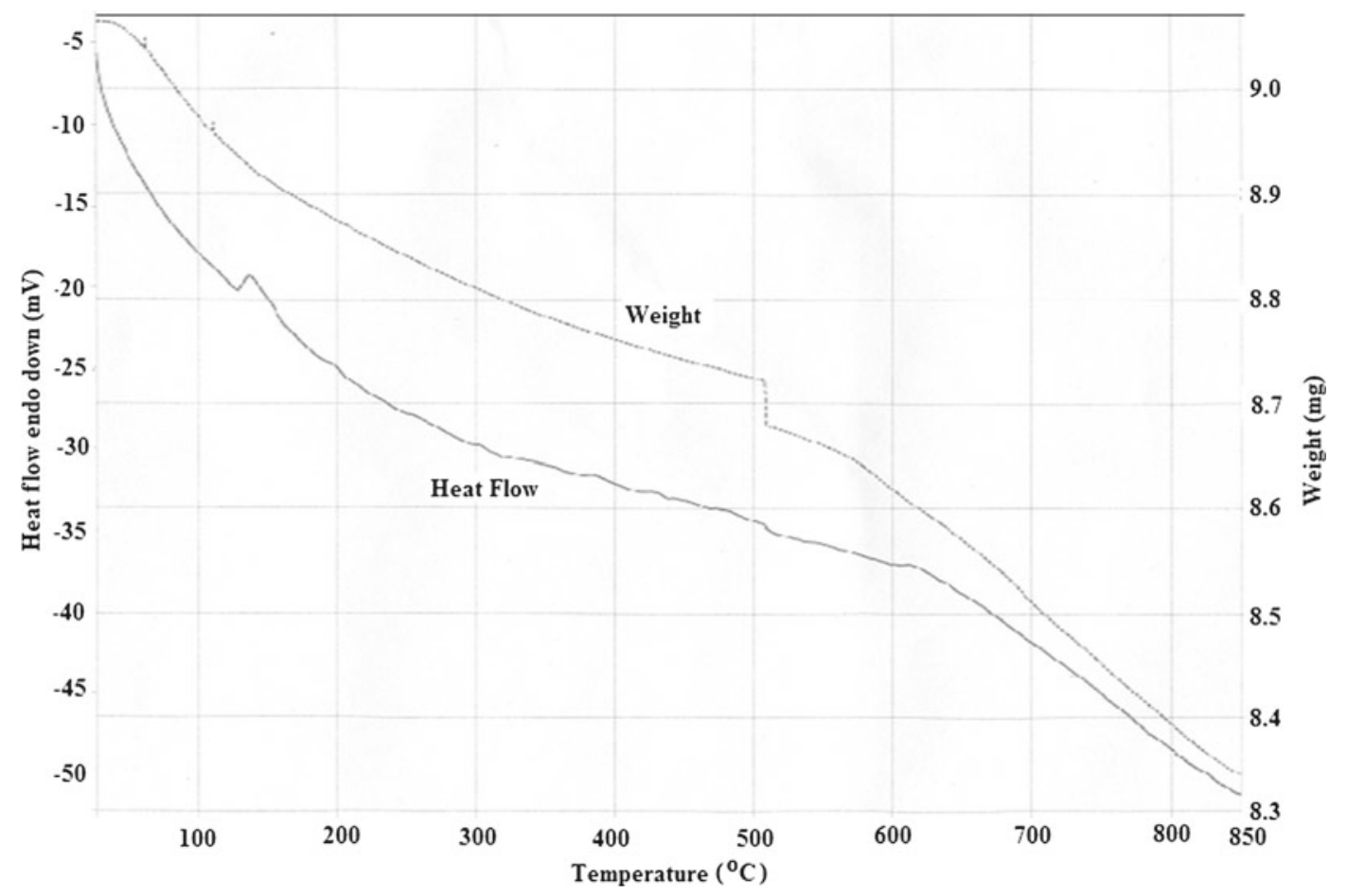

Figure 5. DTA-TGA curve for $\mathrm{BaSnO}_{3}$ sample.

analyser used in the present study. Impedance spectra of the sample in the temperature range of $300-650{ }^{\circ} \mathrm{C}$ have three semicircular arcs. Frequency ranges of these arcs overlap. High frequency arcs at 300 and $350{ }^{\circ} \mathrm{C}$ pass through the origin, but the spectrum at $400{ }^{\circ} \mathrm{C}$ and above does not pass through the origin. An intercept of $\sim 400 \Omega$ is observed which remains almost constant up to the last temperature of measurement, i.e. up to $650{ }^{\circ} \mathrm{C}$. At all temperatures, centres of the semicircles are below the real axis, i.e. depressed semicircles have been observed.

Total impedance of a polycrystalline has contributions of grain $(\mathrm{g})$ and grain boundaries $(\mathrm{gb})$ and sample/electrode interface (el). In impedance plots of the synthesized sample (in the temperature range of $300-650{ }^{\circ} \mathrm{C}$ ), three arcs have been observed and their characteristics frequencies, $\omega_{0}\left(\omega_{0}=\right.$ $\left.1 / \rho \varepsilon_{\mathrm{o}} \varepsilon_{\mathrm{r}}\right)$ differ significantly. The question of whether $\omega_{\mathrm{o}, \mathrm{g}}$, $\omega_{\mathrm{o}, \mathrm{gb}}$ and $\omega_{\mathrm{o}, \mathrm{el}}$ are significantly different from one another reduces to the question of whether or not the products $\left(\rho_{\mathrm{g}} \varepsilon_{\mathrm{g}}\right)$, $\left(\rho_{\mathrm{gb}} \varepsilon_{\mathrm{gb}}\right)$ and $\left(\rho_{\mathrm{el}} \varepsilon_{\mathrm{el}}\right)$ differ significantly. While resistances of materials cover many orders of magnitude, dielectric constants do not vary that significantly. Thus, it is reasonable to make the assumption that $\varepsilon_{\mathrm{g}} \sim \varepsilon_{\mathrm{gb}} \sim \varepsilon_{\mathrm{el}}$ and the question reduces further to whether or not $\rho_{\mathrm{g}}, \rho_{\mathrm{gb}}$ and $\rho_{\mathrm{el}}$ are significantly different from one another. A material in which $\sigma_{\mathrm{g}}>$ $\sigma_{\mathrm{gb}}>\sigma_{\mathrm{el}}$ (by definition $\rho_{\mathrm{el}}>\rho_{\mathrm{gb}}>\rho_{\mathrm{g}}$ ), in turn implies that $\omega_{\mathrm{o}, \mathrm{el}}<\omega_{\mathrm{o}, \mathrm{gb}}<\omega_{\mathrm{o}, \mathrm{g}}$. Consequently, three arcs will be present in a complex plane impedance plot. The higher frequency arc is attributed to the grain (bulk) response and low frequency arc is attributed to electrode response and the semicircle between grain and electrode is attributed to the grain boundaries response. The resistance of each arc is given by the distance across the real axis that each arc extends. In addition, the equivalent capacitance, $C$ of each arc is given by $\left(R \omega_{0}\right)^{-1}$. The values of resistances and capacitances at different temperatures are calculated from manual fitting of the data and are given in table 3. It is already mentioned that in impedance plot of a polycrystalline material, separate arcs for grains and grain boundaries appear when the condition $\rho_{\mathrm{gb}}>\rho_{\mathrm{g}}$ is satisfied. If materials have typical microstructure, i.e. $g / G<1$ (where $G$, average diameter of the grains and $g$, grain boundaries thickness), resistivity of grains and grain boundaries can be obtained by using the relations:

$$
\begin{aligned}
& \rho_{\mathrm{g}}=(A / L) \times R_{\mathrm{g}}, \\
& \rho_{\mathrm{gb}}=(A / L) \times(G / g) \times R_{\mathrm{gb}},
\end{aligned}
$$

where $R_{\mathrm{g}}$ and $R_{\mathrm{gb}}$ are resistances corresponding to high and intermediate frequencies arcs, respectively, and $A$, the crosssectional area of the sample, $L$ the sample length. Moreover, when the condition $\varepsilon_{\mathrm{g}} \sim \varepsilon_{\mathrm{gb}}$ is satisfied, then ratio of capacitance of high and intermediate frequencies arcs is $\left(C_{\mathrm{g}} / C_{\mathrm{gb}}=\right.$ $g / G)$ (Haile et al 1998).

The best manual fitting of the impedance data of sample at $350{ }^{\circ} \mathrm{C}$ yielded parameters: $R_{\mathrm{g}}=20500 \Omega, C_{\mathrm{g}}=2 \cdot 2 \times$ $10^{-11} \mathrm{~F}, R_{\mathrm{gb}}=18000 \Omega$ and $C_{\mathrm{gb}}=1.1 \times 10^{-9} \mathrm{~F}$, geometric factor $A / L=3.14 \mathrm{~cm}$ and $C_{\mathrm{g}} / C_{\mathrm{gb}}=g / G=2.0 \times 10^{-2}$. Resistivity of grains, $\rho_{\mathrm{g}}=(A / L) \times\left(R_{\mathrm{g}}\right)=6.43 \times 10^{4} \Omega$-cm, $\rho_{\mathrm{gb}}=(A / L) \times\left(R_{\mathrm{gb}}\right) \times(G / g)=2.83 \times 10^{6} \Omega$-cm and $\rho_{\mathrm{t}}=$ $(A / L) \times\left(R_{\mathrm{t}}\right)=1.33 \times 10^{5} \Omega$-cm. It is observed that though the resistance of grain boundaries is lower than the grain, resistivity of grain boundaries is two orders of magnitude 


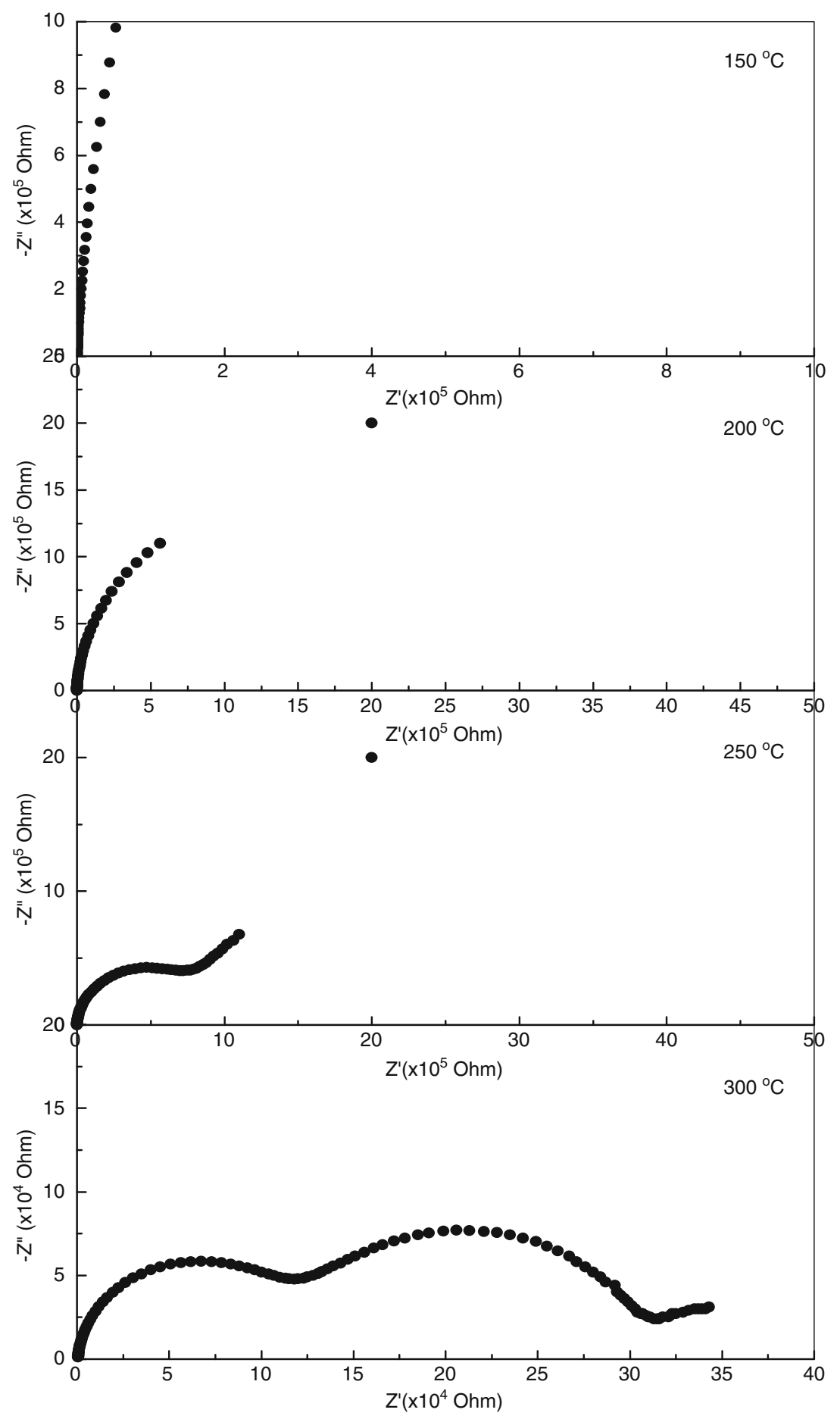

Figure 6. Complex plane impedance plots at few temperatures.

higher than that of the grains. Due to this fact, semicircular arcs for grains and grain boundaries are separated out in the impedance plots (figure 6).

Variation of logarithm of resistance of grains $\left(R_{\mathrm{g}}\right)$, grain boundaries $\left(R_{\mathrm{gb}}\right)$ and electrode $\left(R_{\mathrm{el}}\right)$ with inverse of temperature is shown in figure 7. Two linear regions with different slopes in two different temperature regions have been observed. These two temperature regions are denoted as region I $\left(300-450{ }^{\circ} \mathrm{C}\right)$ and region II $\left(450-650{ }^{\circ} \mathrm{C}\right)$. Linear behaviour of resistances in both the temperature regions indicates that these resistances obey Arrhenius relation given by

$$
R=R_{\mathrm{o}} \exp \left(E_{\mathrm{a}} / k_{\mathrm{b}} T\right),
$$

where $R_{\mathrm{o}}$ is pre-exponential factor, $E_{\mathrm{a}}$ the activation energy and $k_{\mathrm{b}}$ the Boltzmann's constant. 


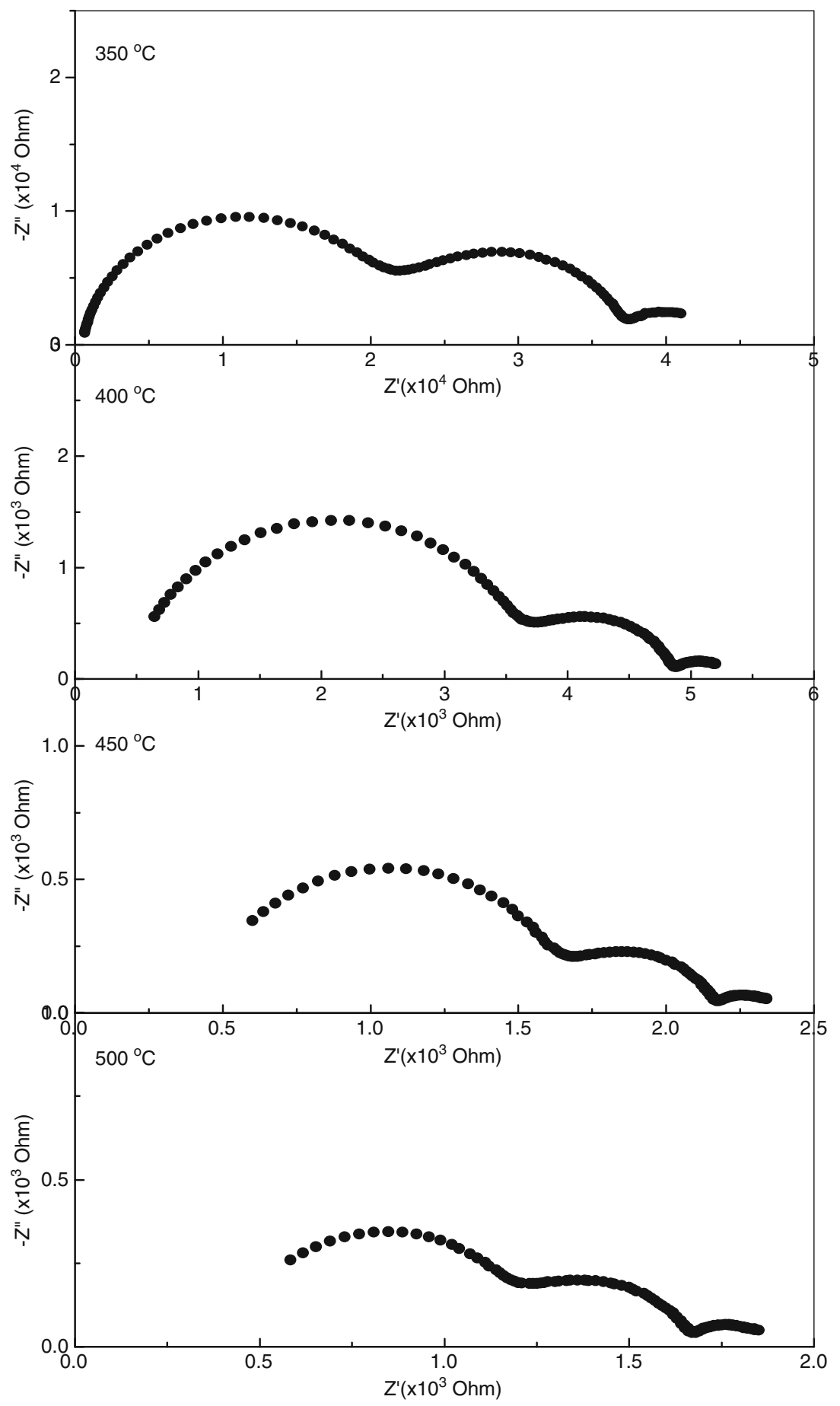

Figure 6. (Continued)

Activation energy in both the temperature regions are obtained by least square fitting of the data and are recorded in table 4 . The value of activation energy in the low temperature region varies from 1.14 to $1.39 \mathrm{eV}$ and in high temperature region from 0.37 to $0.51 \mathrm{eV}$.

The sample in the present study has been synthesized by solid state ceramic route at $1300{ }^{\circ} \mathrm{C}$, therefore, there is a possibility that oxygen leaves the lattice according to equation given below:

$$
\mathrm{O}_{\mathrm{o}} \Leftrightarrow \frac{1}{2} \mathrm{O}_{2}+\mathrm{V}_{\mathrm{o}}^{\bullet \bullet}+2 e^{\prime} .
$$

Therefore, the possibility of oxygen vacancies in the sample cannot be ruled out. It is reported that oxygen vacancies 


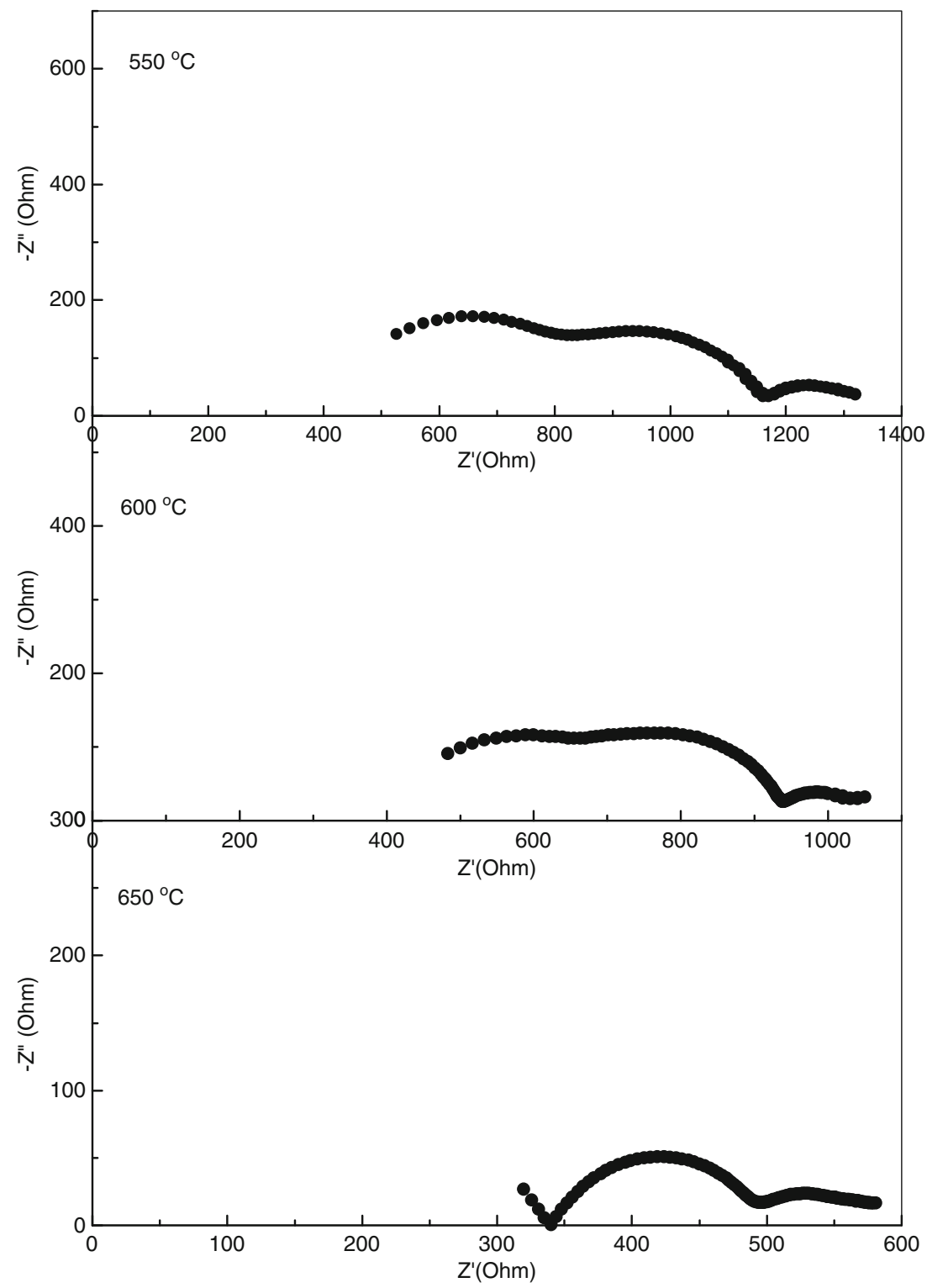

Figure 6. (Continued).

Table 3. Resistance and capacitance values obtained from complex plane impedance plots (figure 6) for $\mathrm{BaSnO}_{3}$.

\begin{tabular}{|c|c|c|c|c|c|c|c|c|c|}
\hline \multirow[b]{2}{*}{$\begin{array}{l}\text { Temperature } \\
\left({ }^{\circ} \mathrm{C}\right)\end{array}$} & \multicolumn{3}{|c|}{ Bulk (g) } & \multicolumn{3}{|c|}{ Grain boundaries (gb) } & \multicolumn{3}{|c|}{ Interfacial (el) } \\
\hline & $\begin{array}{l}R_{\mathrm{g}} \\
(\Omega)\end{array}$ & $\begin{array}{c}f_{\mathrm{g}} \\
(\mathrm{kHz})\end{array}$ & $\begin{array}{l}C_{\mathrm{g}} \\
(\mathrm{pF})\end{array}$ & $\begin{array}{l}R_{\mathrm{gb}} \\
(\Omega)\end{array}$ & $\begin{array}{c}f_{\mathrm{gb}} \\
(\mathrm{kHz})\end{array}$ & $\begin{array}{l}C_{\mathrm{gb}} \\
(\mathrm{nF})\end{array}$ & $\begin{array}{l}R_{\mathrm{el}} \\
(\Omega)\end{array}$ & $\begin{array}{c}f_{\mathrm{el}} \\
(\mathrm{Hz})\end{array}$ & $\begin{array}{c}C_{\mathrm{el}} \\
(\mu \mathrm{F})\end{array}$ \\
\hline 200 & $3 \cdot 2 \times 10^{6}$ & - & - & - & - & - & - & - & - \\
\hline 250 & $1.0 \times 10^{6}$ & 9 & 18 & $2.0 \times 10^{6}$ & - & - & - & - & - \\
\hline 300 & $1.4 \times 10^{5}$ & 63 & 18 & $2 \cdot 1 \times 10^{5}$ & $1 \cdot 5$ & 1 & $10 \times 10^{4}$ & 10 & 1 \\
\hline 350 & $2 \cdot 1 \times 10^{4}$ & 353 & 22 & $1.8 \times 10^{4}$ & $8 \cdot 0$ & 1 & $8.4 \times 10^{3}$ & 17 & 1 \\
\hline 400 & $2.9 \times 10^{3}$ & 1995 & 28 & $1.5 \times 10^{3}$ & $36 \cdot 0$ & 3 & $6 \cdot 5 \times 10^{2}$ & 50 & 5 \\
\hline 450 & $1.2 \times 10^{3}$ & 3981 & 35 & $7.5 \times 10^{2}$ & $79 \cdot 4$ & 3 & $3.0 \times 10^{2}$ & 112 & 5 \\
\hline 500 & $8 \cdot 3 \times 10^{2}$ & 5012 & 38 & $5 \cdot 0 \times 10^{2}$ & 305 & 1 & $2.5 \times 10^{2}$ & 223 & 3 \\
\hline 550 & $3.8 \times 10^{2}$ & 5623 & 75 & $4.7 \times 10^{2}$ & 354 & 1 & $2 \cdot 3 \times 10^{2}$ & 251 & 3 \\
\hline 600 & $3.2 \times 10^{2}$ & 6012 & 84 & $3.4 \times 10^{2}$ & 501 & 1 & $1.6 \times 10^{2}$ & 398 & 3 \\
\hline 650 & - & - & - & $1.6 \times 10^{2}$ & 891 & 1 & $1.0 \times 10^{2}$ & 512 & 3 \\
\hline
\end{tabular}




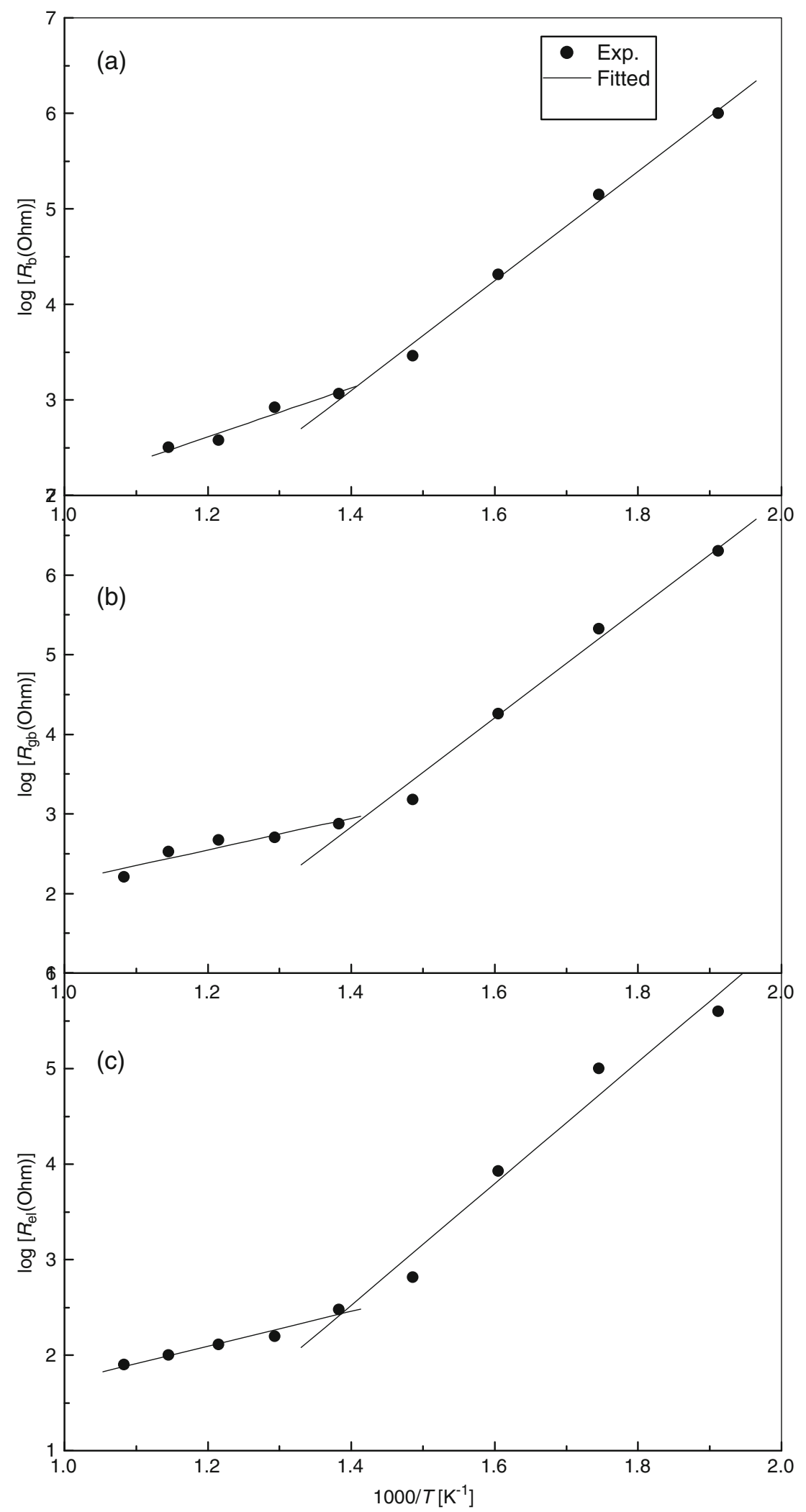

Figure 7. Variation of logarithm of resistance (obtained from figure 6) of (a) grain, (b) grain boundaries and (c) sample/electrode interface with inverse of temperature. 
Table 4. Activation energy for conduction in grain (g), grain boundaries (gb) and electrode (el).

\begin{tabular}{|c|c|c|c|c|c|c|c|c|c|c|}
\hline \multirow{3}{*}{$\begin{array}{l}\text { Temperature } \\
\text { range }\left({ }^{\circ} \mathrm{C}\right)\end{array}$} & \multicolumn{10}{|c|}{ Activation energy $(\mathrm{eV})$ obtained from } \\
\hline & \multicolumn{3}{|c|}{ Figure 7} & \multicolumn{3}{|c|}{ Figure 9} & \multicolumn{3}{|c|}{ Figure 10} & \multirow{2}{*}{$\frac{\text { Figure } 11}{\rho_{\mathrm{t}}}$} \\
\hline & $R_{\mathrm{g}}$ & $R_{\mathrm{gb}}$ & $R_{\mathrm{el}}$ & $R_{\mathrm{g}}$ & $R_{\mathrm{gb}}$ & $R_{\mathrm{el}}$ & $\tau_{\mathrm{g}}$ & $\tau_{\mathrm{gb}}$ & $\tau_{\mathrm{el}}$ & \\
\hline $300-500$ & $1 \cdot 14$ & $1 \cdot 36$ & 1.26 & $1 \cdot 14$ & $1 \cdot 39$ & $1 \cdot 32$ & 1.04 & $0 \cdot 87$ & 0.52 & 1.23 \\
\hline $500-650$ & $0 \cdot 51$ & $0 \cdot 37$ & $0 \cdot 38$ & $0 \cdot 51$ & 0.41 & 0.42 & - & $0 \cdot 87$ & 0.52 & $0 \cdot 51$ \\
\hline
\end{tabular}

$\left(\mathrm{V}_{\mathrm{o}}^{\bullet \bullet}\right)$ are highly mobile in pervoskite structure and activation energy for diffusion of these vacancies is $\sim 1 \mathrm{eV}$. Therefore, conduction in low temperature range (region I) is proposed to take place due to motion of doubly ionized oxygen vacancies $\left(\mathrm{V}_{\mathrm{o}}^{\bullet \bullet}\right)$ (Murugaraj et al 1997; Lu et al 2000).

This sample has a porosity of $\sim 20 \%$, hence, if electrical properties are measured in a humid atmosphere, $\mathrm{H}_{2} \mathrm{O}$ molecules can be adsorbed on the surface of the material. As mentioned above, this material has sufficient amount of oxygen vacancies $\left(\mathrm{V}_{\mathrm{o}}^{\bullet \bullet}\right)$ and lattice oxygen $\left(\mathrm{O}_{0}^{x}\right)$ which leads to the formation of an interstitial proton $(\mathrm{OH})^{\bullet}$ associating with neighbouring $\mathrm{O}_{\mathrm{o}}^{x}$ according to the following equation:

$$
\mathrm{H}_{2} \mathrm{O}(g)+\mathrm{V}_{\mathrm{o}}^{\bullet \bullet}+\mathrm{O}_{\mathrm{o}}^{x} \Leftrightarrow 2(\mathrm{OH})_{i}^{\bullet} .
$$

The interstitial proton $(\mathrm{OH})_{i}^{\bullet}$ may hop around the oxygen vacancies, $\mathrm{V}_{\mathrm{o}}^{\bullet \bullet}$. In the literature, activation energy for proton conduction in pervoskite materials is reported to be between 0.40 and $0.50 \mathrm{eV}$. Activation energy in the high temperature range (region II) of the sample lies between 0.39 and $0.52 \mathrm{eV}$ (Kreuer 1999, 2003). Hence, it is proposed that conduction in the high temperature range (region II) is due to migration of protonic defect. Similar activation energy of all the three resistances shows that sufficient amount of protons $(\mathrm{OH})_{i}^{\bullet}$ are present in the bulk (grain) of the material, i.e. adsorption of water molecule is not limited to the surface, but has penetrated through grains. It is worthwhile to mention that in the synthesis of this sample, water has not been used at any stage.

It is reported in the literature that electrical properties and impedance behaviour of a ceramic oxide is a phase-sensitive parameter. Appearance of more than one semicircle in complex plane impedance plots (in figure 6) may be due to presence of another (second) phase (Macdonald 1987). However, in the present study, variation of resistances of all the three contributions is similar. The three resistances, $R_{\mathrm{g}}$, $R_{\mathrm{gb}}$ and $R_{\mathrm{el}}$ follow exactly similar behaviour with almost same activation energy in both the temperature regions. This suggests that the conduction species (phases) responsible for all the three regions are similar. Due to difference in the resistivity of grain and grain boundaries, ionic charge carriers may deplete and accumulate at the interface of grain and grain boundaries. Development of space charge region increases as the size of grain decreases. A brick layer model of grain boundaries with space charge effect, i.e. total width of grain boundaries is divided into two parts, grain boundaries core $(g b c)$ and space charge zone $(s c z)$. Thus, a polycrystalline material can have three electrically different regions viz. grain $(g)$, space charge zone $(s c z)$ and grain boundaries core ( $g b c)$ (Park et al 2009). Similar conduction behaviour of the three resistances corresponding to the three semicircles in figure 6 indicates that the third semicircle (in lowest frequency range) may be due to the presence of interface at grain-grain boundaries rather than sample-electrode interface.

Figure 8 shows variation of real part of impedance $\left(Z^{\prime}\right)$ as a function of frequency at three different temperatures. Similar behaviour is observed at higher temperatures also. Presence of three relaxation processes is clearly seen in these plots. It is also clear that relaxation time of these processes is temperature-dependent. The trend of impedance vs frequency plot provides an indication of increasing conduction with frequency and temperature (i.e. negative temperature coefficient (NTC) of resistance behaviour typical of semiconductors). Total impedance at $10 \mathrm{~Hz}$ frequency (since $10 \mathrm{~Hz}$ frequency data is very much close to d.c. value) at different temperatures is obtained from figure 8. Using these data, total d.c. resistivity of the sample is calculated at different temperatures, to attain a maximum value of $3 \cdot 2 \times$ $10^{3} \Omega$-cm at $650^{\circ} \mathrm{C}$. This is a very low resistivity when compared with a resistivity of $1.3 \times 10^{9} \Omega$-cm at $150^{\circ} \mathrm{C}$, indicating a jump of nearly six orders of magnitude. The variation of logarithm of total resistivity, $\rho_{\mathrm{t}}$, with inverse of temperature is shown in figure 9. Two linear regions (with respect to temperature) with different slopes have been observed. These two temperature regions are the same as in figure 7 . Linear behaviour of resistivity in both the temperature regions indicates that the total resistivity also obeys Arrhenius relation given by

$$
\rho=\rho_{\mathrm{o}} \exp \left(E_{\mathrm{a}} / k_{\mathrm{b}} T\right) .
$$

Activation energy in both the temperature regions is obtained by least square fitting of the data and recorded in table 4 . The value of activation energy in the low temperature range is $1.14 \mathrm{eV}$, whereas in high temperature range, it is $0.37 \mathrm{eV}$. This observation supports that overall conduction in the low temperature region $\left(300-450{ }^{\circ} \mathrm{C}\right)$ is due to motion of doubly ionized oxygen vacancies $\left(\mathrm{V}_{\mathrm{o}}^{\bullet \bullet}\right)$, whereas in higher temperature range $\left(450-600{ }^{\circ} \mathrm{C}\right)$ it occurs due to migration of protonic defect $(\mathrm{OH})^{\bullet}$.

Variation of $Z^{\prime \prime}$ with logarithm of frequency at different temperatures is shown in figure 10. It is observed that at and above $300{ }^{\circ} \mathrm{C}$, three peaks are present in these plots. Position of each peak shifts towards higher frequency side with increasing temperature. The heights of these peaks decrease with increase in temperature. A typical peak broadening 
which is slightly asymmetrical in nature can also be observed with rise in temperature. Broadening in low frequency and intermediate frequency peaks is more than broadening in high frequency peak. Moreover, broadening in peak is independent of temperature. This suggests that there is a spread of relaxation time, i.e. the temperature-dependent electrical relaxation phenomenon exists in the material. However, for samples in the present system, FWHM is $>1 \cdot 144$ decades for all the three peaks, which is attributed to the distribution of relaxation time.

Resistances of grain, grain boundaries and electrode have been obtained by manually fitting of data as shown in

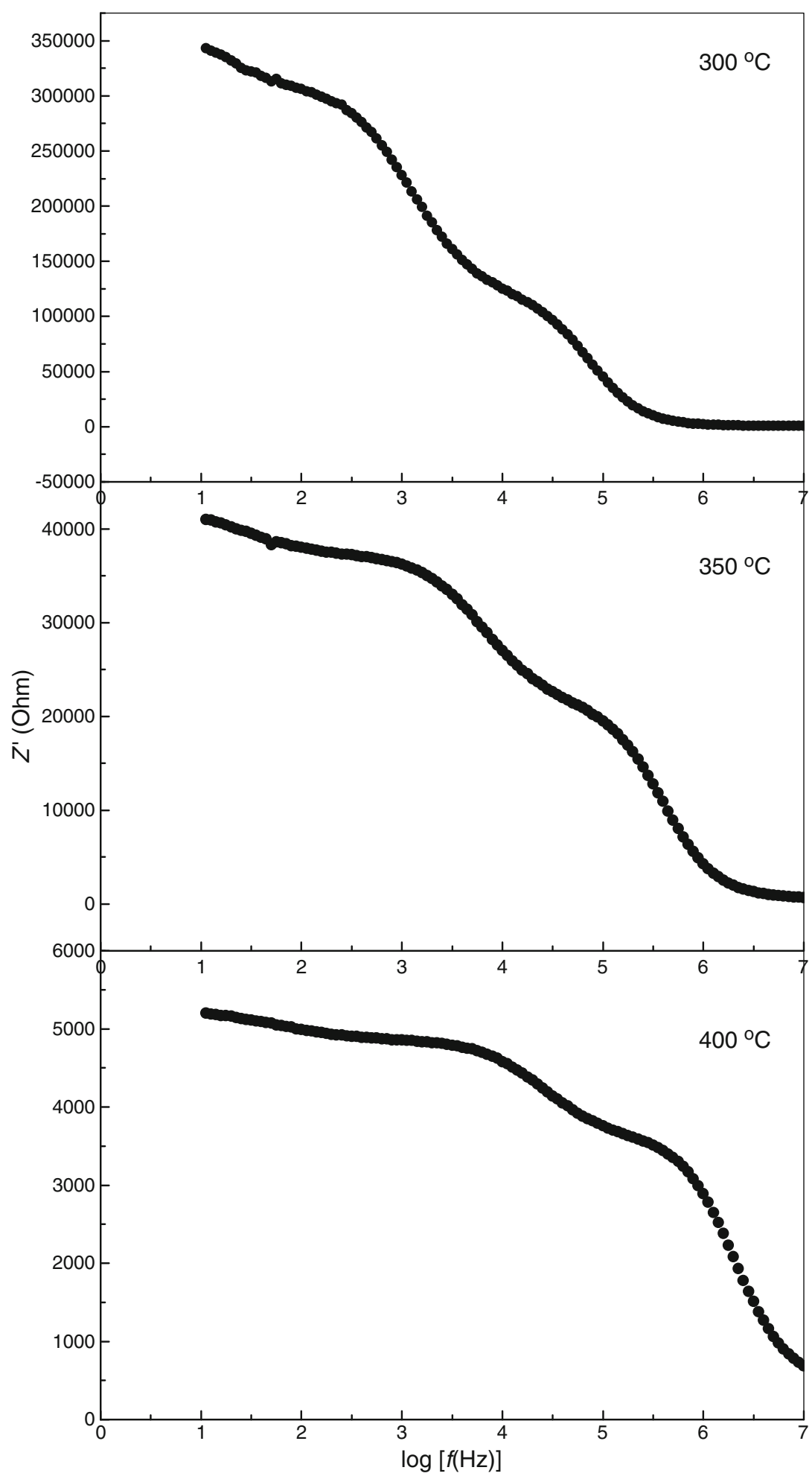

Figure 8. Variation of $Z^{\prime}$ with logarithm of frequency at three different temperatures. 


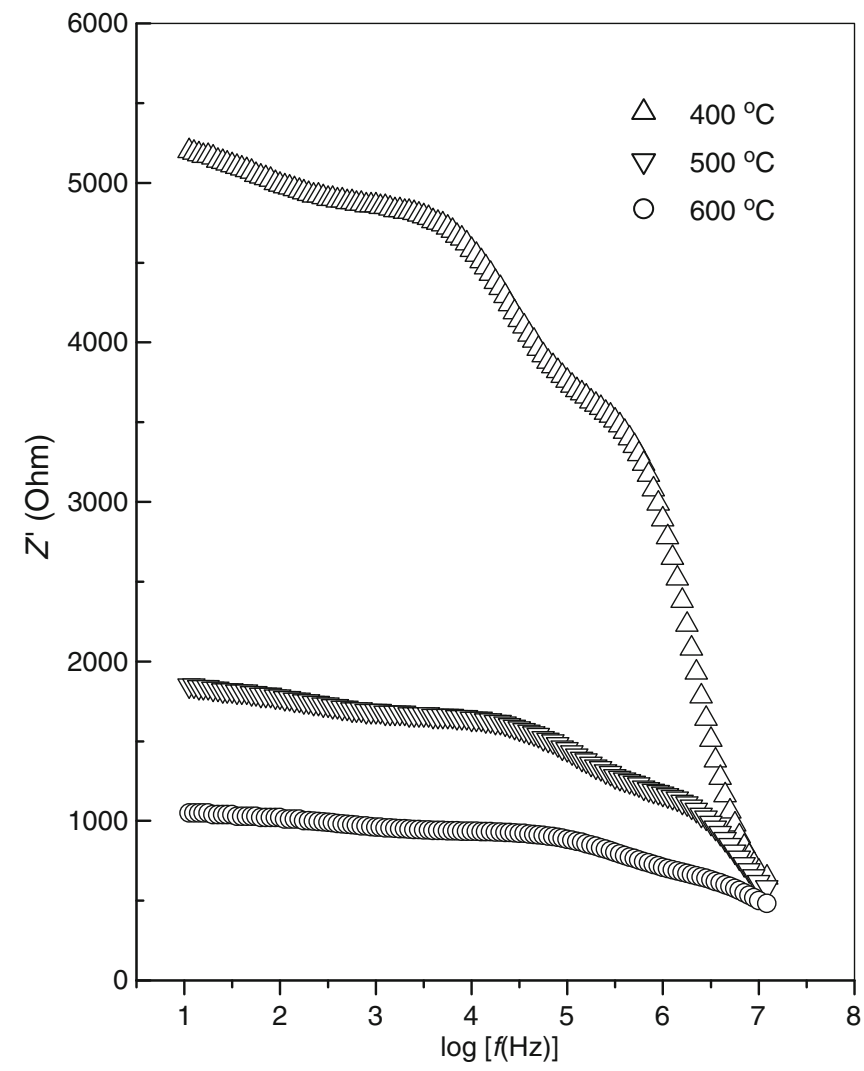

Figure 8. (Continued).

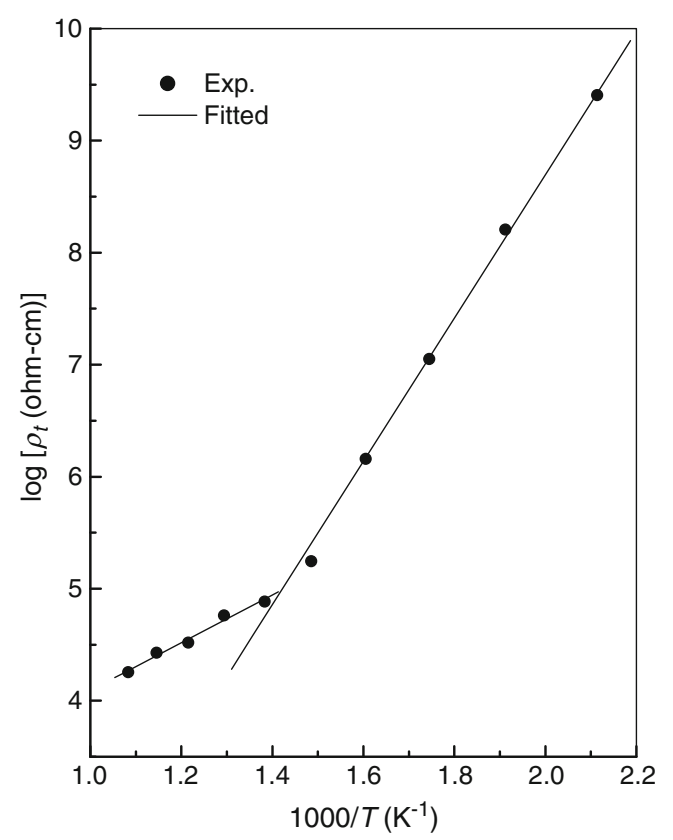

Figure 9. Variation of logarithm of total resistivity with inverse of temperature.

figure 6. Therefore, there is a possibility of error which may lead to an error in determination of activation energy and hence the interpretation in conduction mechanism. A peak is

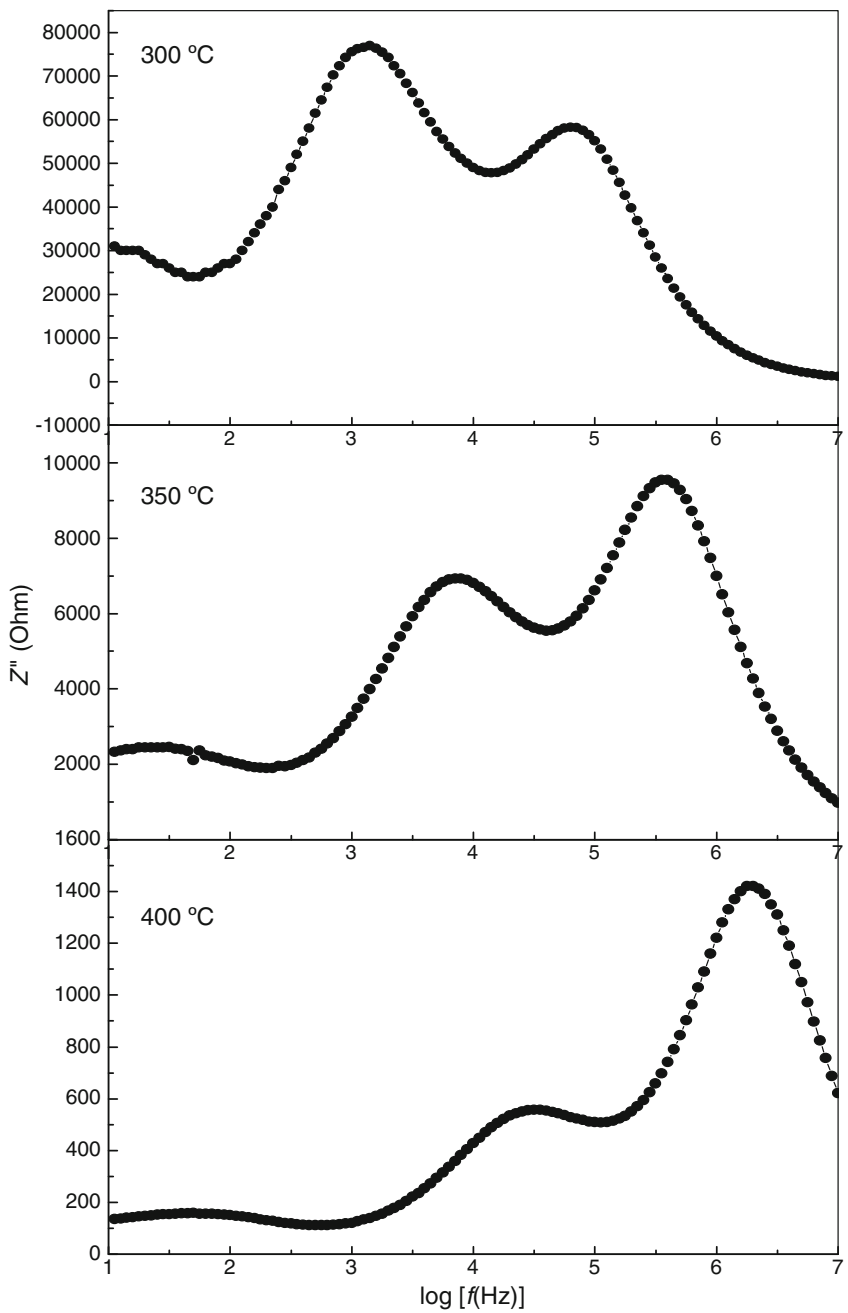

Figure 10. Variation of $Z^{\prime \prime}$ with logarithm of frequency at a few temperatures.

observed in $Z^{\prime \prime}$ vs $\log f$ plots when the relation $\omega \tau=1$ is satisfied ( $\omega$ - angular frequency is equal to $2 \pi f, f$ being the frequency $(\mathrm{Hz})$ and $\tau$ the relaxation time). It is clear from (2) that height of peak in $Z^{\prime \prime}$ vs $\log f$ plots (figure 10) for lower, intermediate and higher frequencies is $R_{\mathrm{g}} / 2, R_{\mathrm{gb}} / 2$ and $R_{\mathrm{el}} / 2$, respectively. Using this fact once again, values of resistances of grain $(\mathrm{g})$, grain boundaries $(\mathrm{gb})$ and electrode (el) have been calculated and given in table 5; the corresponding frequencies and capacitances are also given. Variation of resistances with inverse of temperature is shown in figure 11. Activation energies obtained from this plot are given in table 4 . The value of activation energy estimated from figure 11 (in both the temperature regions) when compared with activation energy value obtained from figure 7 , is observed to have approximately the same value, well within experimental error. This result possibly provides an indication that interpretation in the conduction mechanism is not affected by obtaining resistance value by manual fitting of the data in figure 6.

Relaxation frequency and hence relaxation time $(\tau)$ is a parameter that depends only on the intrinsic properties of 


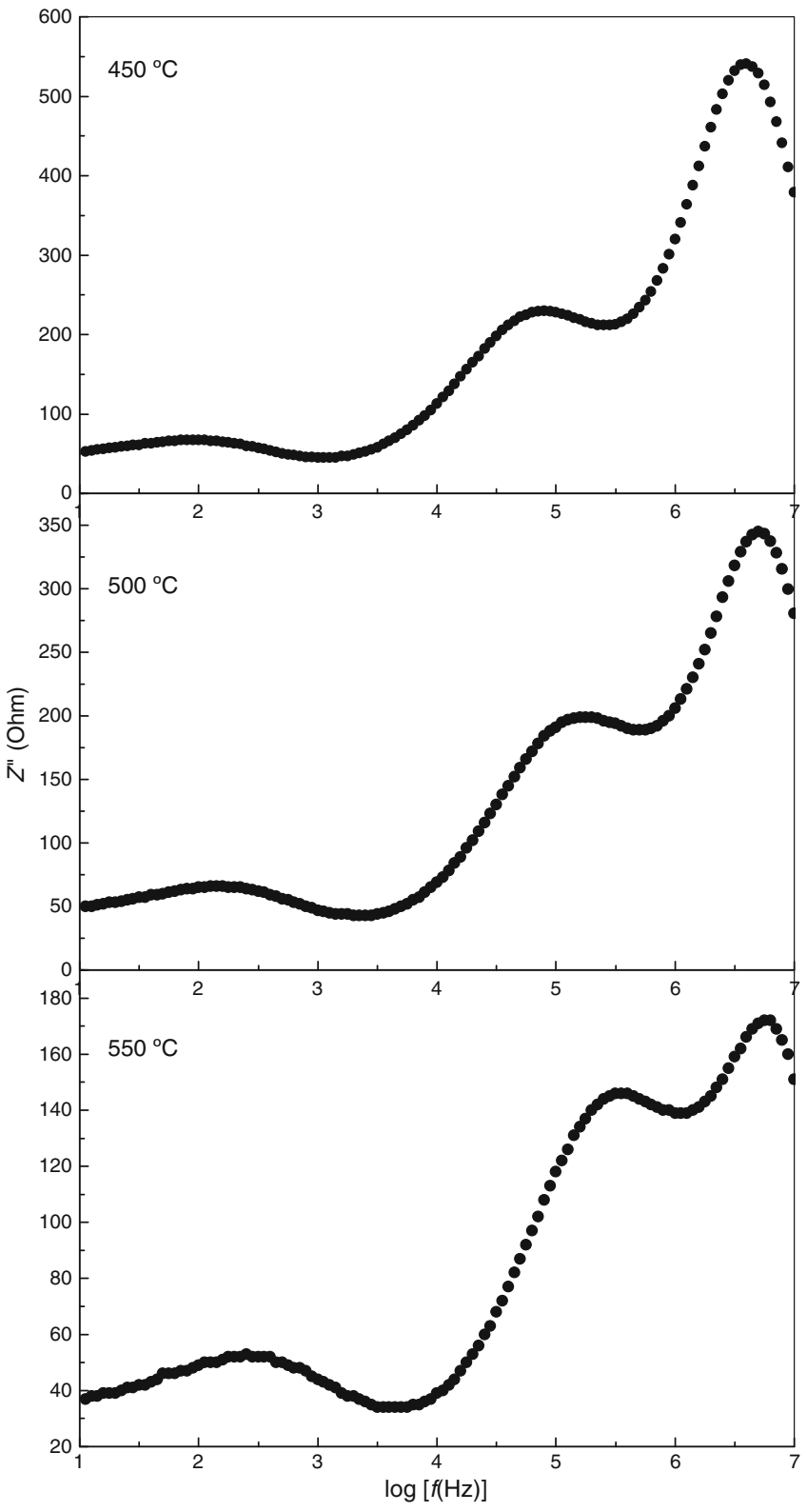

Figure 10. (Continued). materials and not on the sample's geometrical features. The term 'intrinsic properties' of the material refers to the properties attributed to the structural/microstructural, i.e. grain interior or bulk. These properties govern the distribution of resistance and capacitance ultimately depends on relaxation. So, the results obtained using impedance analysis are basically unambiguous and provide a time picture of the sample electrical behaviour.

In figure 10, the position of peaks shifts towards higher frequency side with increasing temperature. A peak is observed when the relation $\omega \tau=1$ is satisfied $(\omega-$ angular frequency is equal to $2 \pi f, f$ being the frequency $(\mathrm{Hz})$ and $\tau$,

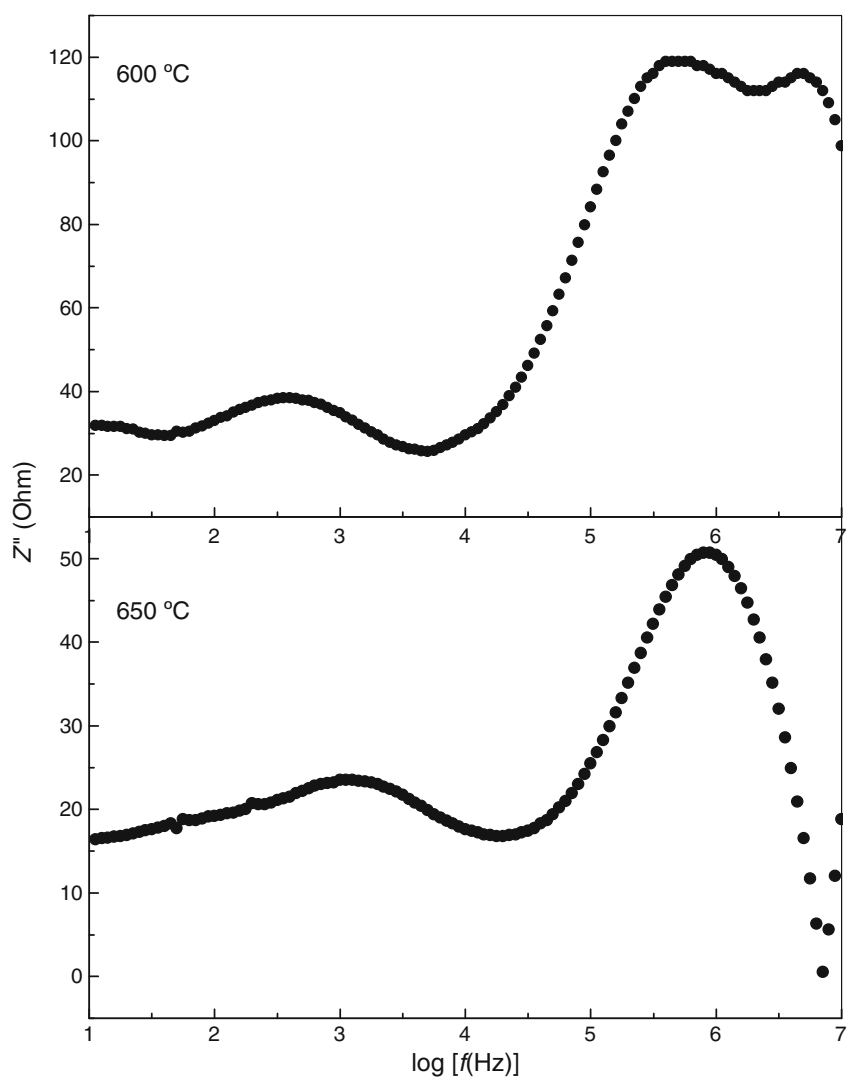

Figure 10. (Continued).

Table 5. Resistance and capacitance values obtained from $Z^{\prime \prime}$ vs $\log f$ plots (figure 10) for $\mathrm{BaSnO}_{3}$.

\begin{tabular}{|c|c|c|c|c|c|c|c|c|c|}
\hline \multirow[b]{2}{*}{$\begin{array}{l}\text { Temperature } \\
\left({ }^{\circ} \mathrm{C}\right)\end{array}$} & \multicolumn{3}{|c|}{ Bulk (g) } & \multicolumn{3}{|c|}{ Grain boundaries (gb) } & \multicolumn{3}{|c|}{ Interfacial (el) } \\
\hline & $\begin{array}{l}R_{\mathrm{g}} \\
(\Omega)\end{array}$ & $\underset{(\mathrm{kHz})}{f_{\mathrm{g}}}$ & $\begin{array}{l}C_{\mathrm{g}} \\
(\mathrm{pF})\end{array}$ & $\begin{array}{l}R_{\mathrm{gb}} \\
(\Omega)\end{array}$ & $\begin{array}{c}f_{\mathrm{gb}} \\
(\mathrm{kHz})\end{array}$ & $\begin{array}{l}C_{\mathrm{gb}} \\
(\mathrm{nF})\end{array}$ & $\begin{array}{l}R_{\mathrm{el}} \\
(\Omega)\end{array}$ & $\begin{array}{c}f_{\mathrm{el}} \\
(\mathrm{Hz})\end{array}$ & $\begin{array}{c}C_{\mathrm{el}} \\
(\mu \mathrm{F})\end{array}$ \\
\hline 300 & $12 \times 10^{4}$ & 63 & 22 & $16 \times 10^{4}$ & $1 \cdot 5$ & 1 & $9.0 \times 10^{4}$ & 10 & 1 \\
\hline 350 & $2.0 \times 10^{4}$ & 353 & 24 & $1.4 \times 10^{4}$ & $8 \cdot 0$ & 1 & $5.4 \times 10^{3}$ & 17 & 2 \\
\hline 400 & $2.9 \times 10^{3}$ & 1995 & 28 & $1.2 \times 10^{3}$ & $36 \cdot 0$ & 4 & $4.0 \times 10^{2}$ & 50 & 8 \\
\hline 450 & $1.10 \times 10^{3}$ & 3981 & 37 & $5.8 \times 10^{2}$ & $79 \cdot 4$ & 4 & $1.5 \times 10^{2}$ & 112 & 9 \\
\hline 500 & $7 \cdot 0 \times 10^{2}$ & 5012 & 46 & $4.6 \times 10^{2}$ & 305 & 1 & $1.2 \times 10^{2}$ & 223 & 6 \\
\hline 550 & $3.4 \times 10^{2}$ & 5623 & 84 & $3.7 \times 10^{2}$ & 354 & 1 & $1.1 \times 10^{2}$ & 251 & 6 \\
\hline 600 & $3.0 \times 10^{2}$ & 6012 & 88 & $2.4 \times 10^{2}$ & 501 & 1 & $7.0 \times 10^{1}$ & 398 & 6 \\
\hline 650 & - & - & - & $1.4 \times 10^{2}$ & 891 & 2 & $5 \cdot 0 \times 10^{1}$ & 512 & 3 \\
\hline
\end{tabular}




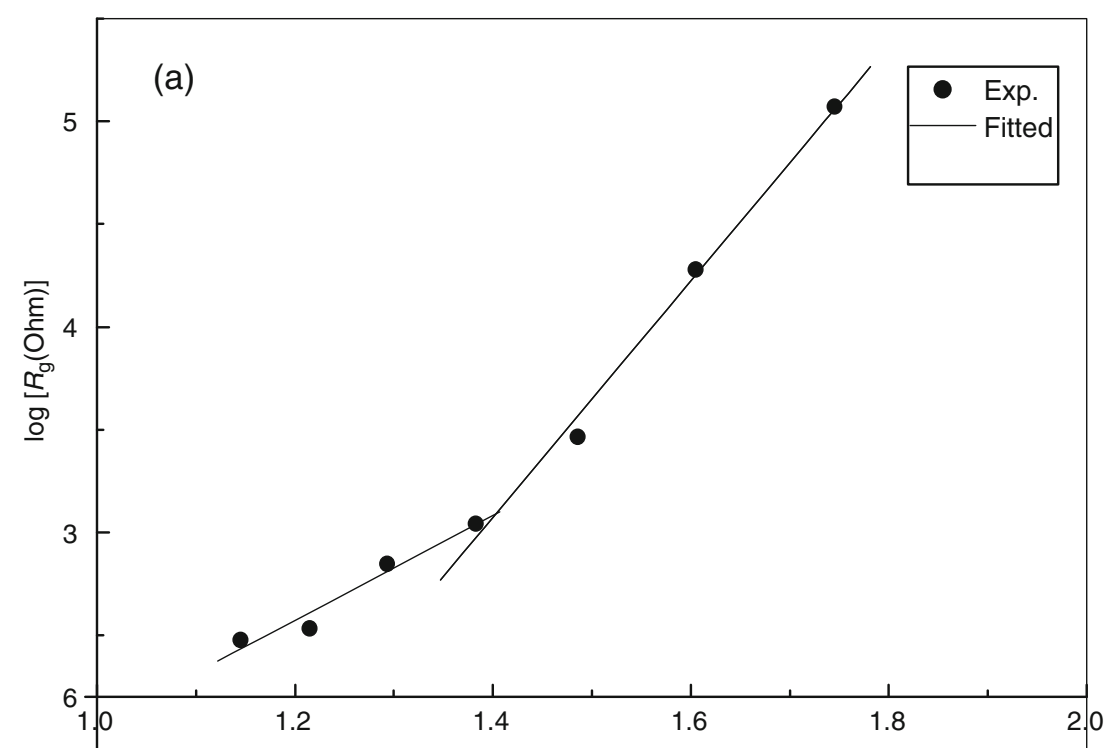

(b)

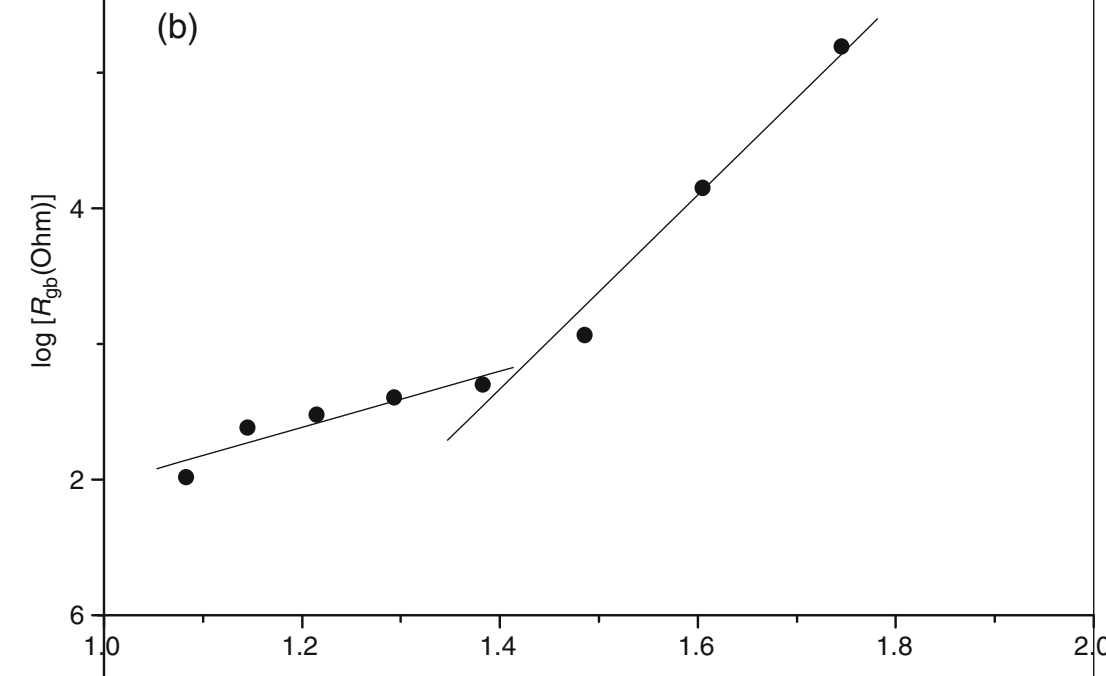

(c)

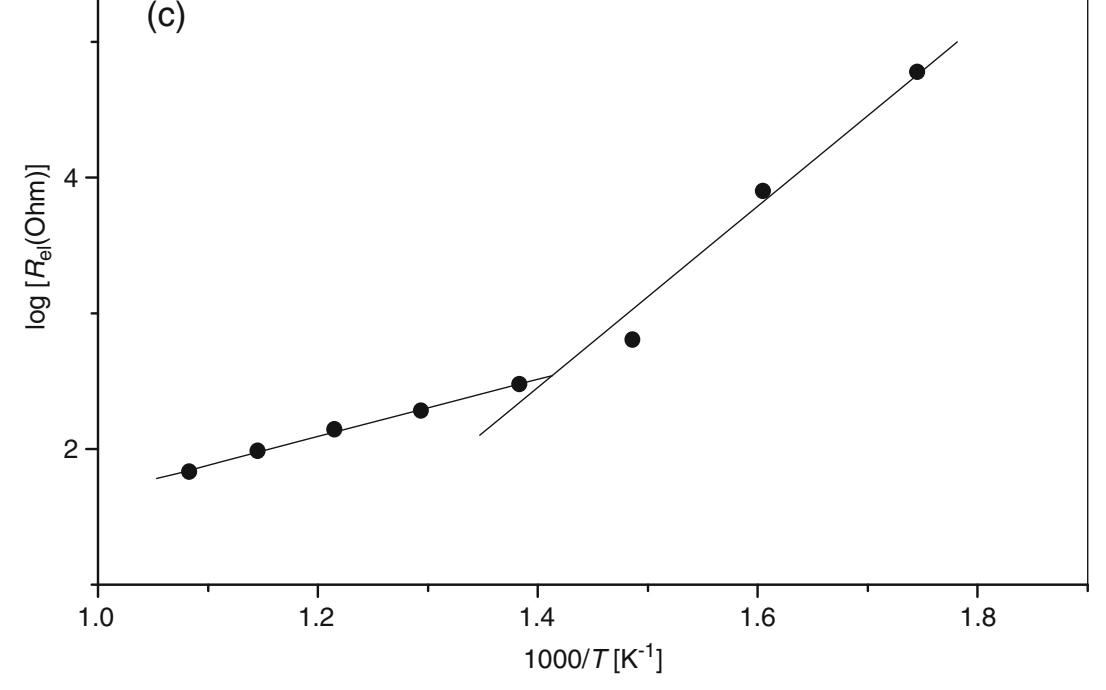

Figure 11. Variation of logarithm of resistance (obtained from figure 10) of (a) grain, (b) grain boundaries and (c) sample-electrode interface with inverse of temperature. 


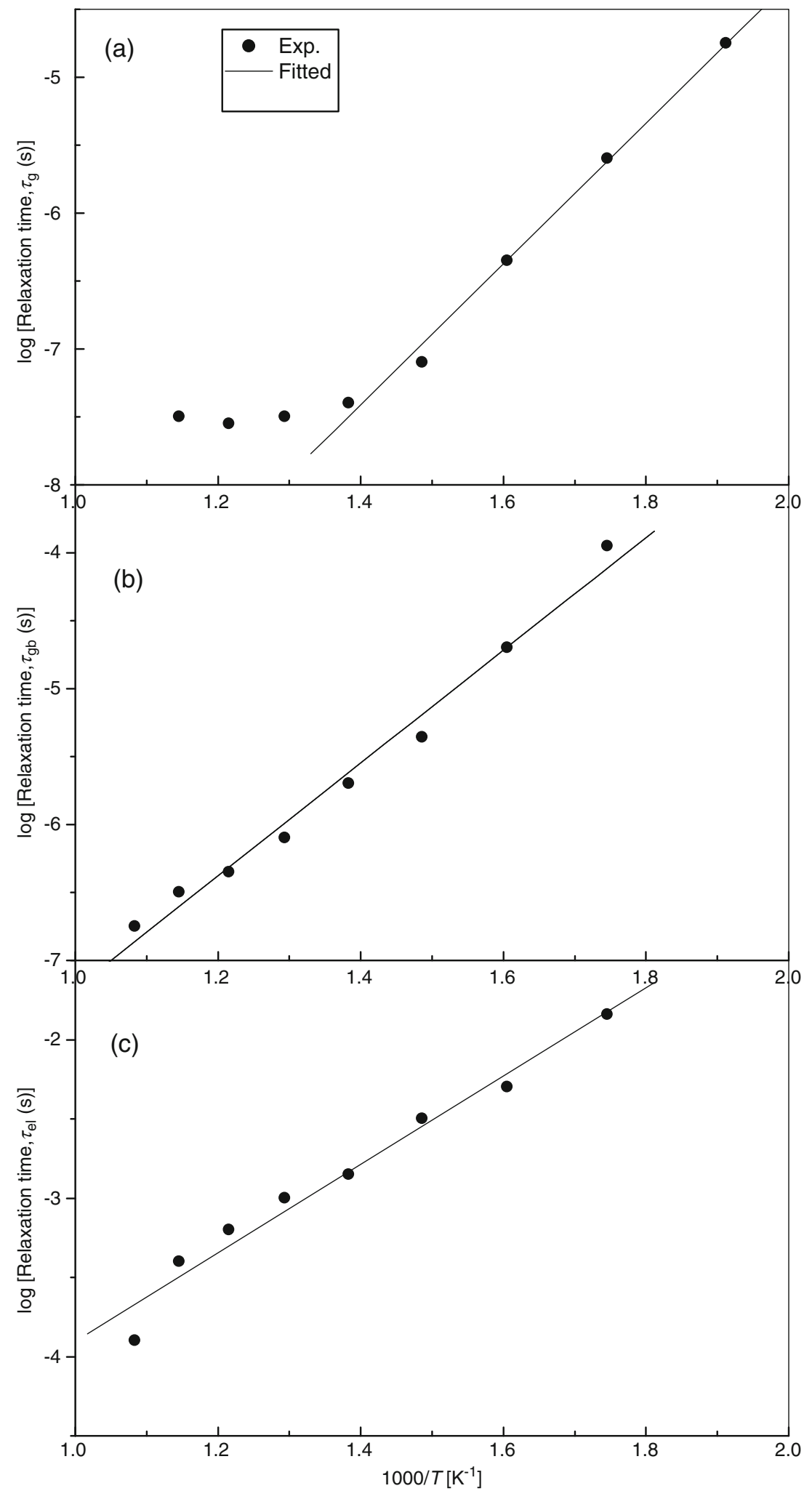

Figure 12. Variation of logarithm of relaxation time (obtained from figure 10) of (a) grain, (b) grain boundaries and (c) sample-electrode interface with inverse of temperature. 
the relaxation time). With increase in temperature, the relation $\omega \tau=1$ is satisfied at higher frequency. The relaxation time $\tau$ for grain, grain boundaries and interface is determined from peak position and plots of $\log \tau$ (relaxation time) with the inverse of temperature for all the three contributions are shown in figure 12. Variation of $\log \tau_{\mathrm{g}}, \tau_{\mathrm{gb}}$ and $\tau_{\mathrm{el}}$ with the inverse of temperature shows single linear region in entire range of temperatures. Linear behaviour of $\log \tau$ with $1000 / T$ indicates that relaxation time obeys Arrhenius relation given by

$$
\tau=\tau_{\mathrm{o}} \exp \left(E_{\tau} / k_{\mathrm{B}} T\right),
$$

where $\tau_{\mathrm{o}}$ is the relaxation time at infinite temperature, $E_{\tau}$ the activation energy for relaxation, $k_{\mathrm{B}}$ the Boltzmann's constant and $T$ the absolute temperature. A linear fit of $\log \tau$ vs $1000 / T$ plots has been used to estimate the activation energy of the material. The values so obtained are recorded in table 4 . This value of activation energy $\left(E_{\tau}\right)$ estimated for grains at low temperature $\left(\leq 450{ }^{\circ} \mathrm{C}\right)$ when compared with activation energy value $\left(E_{\mathrm{a}}\right)$ is observed to have approximately the same value, well within experimental error. This result possibly provides an indication that electrical species (charge carriers) involved in the process of relaxation and conduction for the grains in low temperature range are the same. The value of activation energy of grain boundaries and electrode for relaxation $\left(E_{\tau}\right)$ when compared with the activation energy for conduction $\left(E_{\mathrm{a}}\right)$ values shows marked differences. This result possibly provides an indication that electrical species (charge carriers) involved in the process of relaxation and conduction are different.

\section{Conclusions}

Powder XRD studies of $\mathrm{BaSnO}_{3}$ confirm the formation of single phase cubic structure. Scanning electron microscopy has confirmed the polycrystalline texture of the material with porous microstructure. EDX analysis confirmed the homogeneous nature of the synthesized material. TGA curve of the sample exhibited adsorption of water molecules by the synthesized powder. Presence of protonic defects has been supported by FTIR spectrum of the sample. The a.c. impedance analysis reveals that at higher temperatures, total impedance is the contribution of grain, grain boundaries and electrode. Two temperature ranges with different activation energies have been observed for all the three resistances. Activation energies in both the temperature ranges for the three resistances match well. Therefore, it is concluded that conduction species (phases) responsible for conduction within grain, grain boundaries and electrode are the same. Activation energy estimated from the variation of resistances/total resistivity confirmed that conduction in low temperature region $\left(300-450{ }^{\circ} \mathrm{C}\right)$ is due to thermal diffusion of doubly ionized oxygen vacancies $\left(\mathrm{V}_{\mathrm{o}}^{\bullet \bullet}\right)$, whereas in the high temperature region $\left(450-650^{\circ} \mathrm{C}\right)$, it occurs due to hopping of $(\mathrm{OH})^{\bullet}$ ions.

\section{Acknowledgement}

The author is grateful to the Head, Department of Physics, R. T. M. Nagpur University, Nagpur, for providing facilities to carry out electrical measurements.

\section{References}

Animitsa I, Dogodaeva E, Trasova N, Korsareva O and Neiman A 2011 Solid State Ionics 1851

Azad A M and Hon N C 1998 J. Alloys Compd. 27095

Bevillon E, Geneste G, Chesnaud A, Wang J and Dezanneau G 2008 Ionics 141293

Borse P H, Joshi U A, Ji S M, Jang J S, Lee J S, Jeong F D and Kim H G 2007 Appl. Phys. Lett. 90034103

Burn I and Neirman S 1984 J. Mater. Sci. 19737

Cava J, Gammel P, Batlog B, Krajewski J J, Peck Jr W F, Rupp Jr W L, Felder R and Van Dover R B 1990 Phys. Rev. B42 4815

Cerda J, Arbiol J, Dezunneau G, Diaz R and Morante J R 2002 Sensor Actuat. B84 21

Deepa A S, Vidya S, Manu P C, Solomon S, John A and Thomas J K 2011 J. Alloys Compd. 5091830

Doroflet C, Popa P D and Lacombi F 2012 Sensor Actuat A173 24

Gopal Reddy V, Manorama S V and Rao V J 2001 J. Mat. Sci.: Mater. Elect. 12137

Haile S M, West D L and Cambell J 1998 J. Mater. Res. 131576

Kocemba I, Jodrzejewska M W, Szychowska A, Rynkowski J and Glowka M 2007 Sensor Actuat. B121 401

Kreuer K D 1999 Solid State Ionics 125285

Kreuer K D 2003 Ann. Rev. Mater. Res. 33333

Kumar A and Choudhary R N P 2007 J. Mat. Sci. 422476

Kumar A, Singh B P, Choudhary R N P and Thakur A K 2005a Mater. Lett. 591880

Kumar A, Singh B P, Choudhary R N P and Thakur A K 2005b J. Alloys Compd. 394292

Kumar A, Singh B P, Choudhary R N P and Kumar A K 2006a Mat. Chem. Phys. 99150

Kumar A, Choudhary R N P, Singh B P and Thakur A K 2006b Ceram. Int. 3273

Kumar A, Choudhary R N P and Singh B P 2007 J. Mater. Sci. 42 8506

Kutty T R N and Vivekanandan R 1987 Mater. Res. Bull. 221457

Larramona G, Gutierrez C, Nunes M R and da Costa F M A 1989 J. Chem. Soc. Faraday Trans. 85907

Lu W and Schmidt H 2007 J. Sol-Gel Tech. 4255

Lu W and Schmidt H 2008 Ceram. Int. 34645

Lu W, Jiang S, Zhou D and Gong S 2000 Sensor Actuat. 8035

Macdonald J R (ed.) 1987 Impedance spectroscopy, emphasizing solid materials and systems (Singapore: Wiley) Ch. 4

MacDonald J R and Johnson W B 1987 Impedance spectroscopy emphasizing solid materials and systems (ed.) J R MacDonald (New York: Wiley \& Sons) p. 1

Murugaraj P, Krurer K D, He T, Schober T and Maier J 1997 Solid State Ionics 981

Ostrick B, Fleischer M, Lampe U and Meixner H 1997 Sensor Actuat. B44 60

Park H J, Kwank C, Lee K H, Lee S M and Lee E S 2009 J. Eur. Ceram. Soc. 292429

Pfaff G, Hildenbrand V D and Fuess H 1998 J. Mater. Sci. Lett. 17 1983

Prokopale O I 1976 Ferroelectrics 14683 
Raevski I P, Prokopalo O I and Kolesnikove S G 1983 Rostov-onDon 531175

Ramdas B and Vijayraghavan R 2010 Bull. Mater. Sci. 3375

Roberto K, Abicht H P, Wultersdorf J and Pippel E 2006 Therm. Chem. Acta 44176

Schober T 1998 Solid State Ionics 1091

Shimizu Y, Narikiyo T, Arai H and Seiyama T 1985 Chem. Lett. 14 377

Smit M G, Goodenough J B, Manthiram A, Taylor R D, Peng W and Kimbal C W 1992 J. Solid State Chem. 98181

Smith A J and Welch A J E 1960 Acta Crystallogr. 13653

Smolensi G A, Iagranovskaya A, Kalinin A M and Fedotova T M 1955 Z. K. Tekh. Fiz. 252134

Song Y J and Kim S 2001 Ind. Engg. Chem. 7183
Tao S, Gao F, Liu X and Sarensen O T 2000 Sensor Actuat. B71 223 Upadhyay S, Parkash O and Kumar D 1997 J. Mater. Sci. Lett. 16 1330

Upadhyay S and Kavita P 2007 Mater. Lett. 611912

Vivekanandan R and Kutty T R N 1990 Mater. Sci. Engg. B6 221

Wang T, Chen X M and Zheng X H 2003 J. Electroceram. 11173

Wang S, Yang Z, Zhou G, Lu M, Zhou Y and Zhang H 2007 J. Mater. Sci. 426819

Wang Y, Chesnaud A, Bevillon E, Yang J and Dezanneau G 2011 Mat. Sci. Engg. B176 1178

Yuan Y, Lu J, Jiang X, Li Z, Yu T, Zou Z and Ye J 2007 Appl. Phys. Lett. 91094107

Zhang Y, Zhang H, Wang Y and Zhang W F 2008 J. Phys. Chem. C112 8553 